\title{
A Study of the Vascular System of Matonia pectinata.
}

\author{
BY \\ A. G. TANSLEY, M.A., \\ Assistant-Professor of Botany, University College, London,
}

AND

MISS R. B. J. LULHAM, B.Sc.

With Plates XXXI, XXXII, and XXXIII, and five Figures in the Text.

\section{Contents.}

\section{INTRODUCTORY}

Young Plants

THE Morphology of the Leaf.

Details of Progressive Complication in the Vascular System :-

(I) Young Plants . . . . . . . . . . . . . . ..$_{482}$

(2) Intermediate Plants . . . . . . . . . . . . . . . . . 490

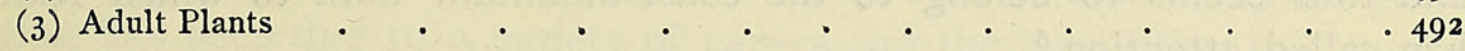

Summary of Progressive Complication in the Vascular System . . . . . 496

Protoxylems. . . . . . . . . . . . . . . . . 503

Nature and Phylogenetic Relations of the Vascular System in Matonia :-

Morphological Position and Origin of the Matonia-type • • • • • 508

Functional Relations of the Vascular System of Matonia in connexion with

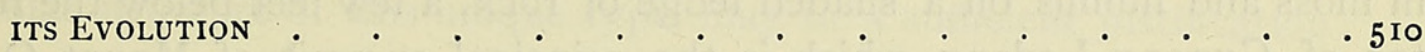

ROOTS . . . . . . . . . . . . . . . . . $^{\mathrm{I} 3}$

MorPhological Status of ' Pith' . . . . . . . . . . . 5 I 4

\section{INTRODUCTORY.}

EVER since the meeting of the British Association at Bristol in 1898 , at which Mr. Seward described ${ }^{1}$ the complicated and striking vascular anatomy of the comparatively rare Malayan fern Matonia pectinata, the problem of relating this apparently unique vascular skeleton to those of other Ferns has been a matter of considerable interest to students of Filicinean vascular morphology.

1 Subsequently published in full, Phil. Trans. B., vol. cxci, p. I7 I, 1899.

[Annals of Botany, Vo1. XIX. No. LXXVI. October, 1905.] 
It was already evident in 1898 that a study of the young plants would throw light on this question ${ }^{1}$, though the importance of the vascular structure of the first-formed stem, especially in Ferns, as furnishing an ontogenetic parallel to the process of evolution of the adult structure, was not at that time so clearly recognized as it is to-day.

It was largely for this reason that I welcomed the opportunity, in January, I90I, of joining Dr. W. H. Lang in his visit to Mount Ophir in the Malay Peninsula, the original locality ${ }^{2}$ for Matonia pectinata, which is particularly abundant on its upper slopes. I can confirm Wallace's description of the habitat of this magnificent Fern, as quoted by Seward ${ }^{3}$. The Matonia is almost confined to open situations on Ophir, covering the comparatively shallow soil overlying the flat or gently sloping rock faces in dense thickets. Its most abundant congener in these thickets is Gleichenia linearis (dichotoma), while Gleichenia flagellaris, Dipteris conjugata, and a little Pteris aquilina are also constantly associated. All these Ferns are characteristic of the open, or of slightly shaded situations. Matonia scarcely penetrates the thick dwarf woods of the upper part of Ophir, though an occasional clump occurs where an opening in the trees allows more light than usual to reach the ground. In Borneo $M$. pectinata occurs on Santuborg and Matang, 3,500 to 3,800 feet above sea-level, situations which seem quite comparable to the Ophir one, though curiously enough it is said to be there confined to old jungle ${ }^{4}$, quite contrary to its occurrence on Ophir. It is also known from various Malay islands at sea-level, and thus seems to belong to the coast-mountain flora to which Ridley has called attention ${ }^{5}$.

\section{Young Plants of Matonia pectinata.}

After considerable search I discovered three young plants embedded in moss and humus on a shaded ledge of rock, a few feet below the rocky top of Gunong Ledang, which is the principal summit of Mount Ophir. These are represented on Plate XXXI, Figs. 4, 5, 6, and 7. The strong resemblance of their fronds to those of older but starved specimens of the plant growing in a deeply shaded crevice below an overhanging rock on the other side of the summit, left no doubt of the identity of these plants, while their small size and the shortness of their rhizomes indicated their comparative youth.

Dr. Lang afterwards found three even younger specimens, which he very kindly handed over to me, in the damp soil by the side of a small stream on Padang Batu. These are represented on Plate XXXI, Figs. I, 2, and 3, and here again the form and venation of the fronds, when compared with the

1 Seward ('99), pp. 180, 18 I.

${ }^{3}$ Seward ('99), p. r 7 I.
2 Wallace, The Malay Archipelago, 1886, p. 30.

4 Seward ('99), p. 174. 5 Ridley ('01). 
older specimens, left no doubt of their identity. The rarity of the young plants of this species compared with the comparative abundance of those of Gleichenia linearis and Dipteris conjugata in similar situations was rather striking. Neither Dr. Lang nor I succeeded in finding any specimens with the prothallus attached, in spite of continued hunting. In addition to the six young plants, I subsequently found some plants with thin rhizomes and small comparatively simple fronds growing in the deep shade of a rock-cleft. These were evidently much older than the oldest of the six, but had been starved owing to want of light and perhaps also to lack of soil.

The specimens thus obtained form a fairly good series, both as regards the gradually increasing complication in the form of the frond, and also, as we shall see presently, in vascular structure.

During my stay on Ophir I naturally took the opportunity of laying in a good stock of material of the adult plant, and after my return to England I sent, at Prof. Weiss's request, a few nodes preserved in spirit to the Owens College, Manchester. In this material Miss Wigglesworth, a pupil of Prof. Weiss, discovered a distinctly more complicated type of structure than that described by Mr. Seward, a type with three concentric amphiphloic siphonostelic cylinders in the rhizome ${ }^{1}$. It thereupon seemed desirable to work through the whole of my stock of material, and Miss Lulham undertook this laborious task.

The results of the investigation, together with those obtained from the young plants ${ }^{2}$, are now presented. The considerable delay in publication has been due to a variety of causes, not the least being the lengthy character of the work. No less than fifty nodes have been examined from the adult plants alone, several thousand sections have been cut, and numerous wax models made. It is hoped that the fairly complete account, which we are now able to give, of the progressive complication in the vascular structure of this unique type, may be a sufficient justification.

\section{A. G. TANSLEY.}

\section{The Morphology of the Leaf.}

A comparison of the fronds borne by the different young plants (Plate XXXI, Figs. I-8) shows considerable variety of form, and, in the larger fronds at least, a mixture of the dichotomous and monopodial types of branching. There is, however, as we shall see, good reason to believe that dichotomy is the primary method.

Plant A (Fig. 1) has one tiny frond which is simply bifid. The larger frond is trifid, and might be considered to consist of a central

1 Grace Wigglesworth, New Phytologist, vol. i, 1902, p. 157.

${ }^{2}$ I am indebted to my wife and to Mis; E. N. Thomas for preparing sections of the six young plants. 
phyllopodium with a right and a left lateral. A microtome series of the top of the petiole and base of the frond, however, reveals a clear dichotomy of the single petiolar strand into two equal trunks, one of which (that belonging to the central lobe) increases in size somewhat, and sends off a branch nearly at right angles, which becomes the midrib of the left-hand lobe. This behaviour of the vascular strands certainly suggests a primary dichotomy, one of the members of which sends off a single branch from its base.

Plant B (Fig. 2) has a small frond with apparently a primary dichotomy, one of whose members remains small, while the other undergoes a secondary dichotomy. The larger frond, on the other hand, if we may judge from the course of the vascular strands, has a middle lobe, from the base of which arise two laterals, each of which branches, whether dichotomously or monopodially it is hard to decide. This frond, assuming the laterals to dichotomize, may be regarded as a sort of prototype of the adult frond.

Plant C (Fig. 3) has both its fronds, and Plant D (Fig. 4) two of its three fronds, clearly showing a primary dichotomy, while the subsequent branching, especially in C, appears to be very largely dichotomous.

Fig. 5 (a detached leaf of Plant E) shows an unusual type of leaf. Fig. 6 (another leaf from E) returns to the type of the larger frond of $B$ (Fig. 2), i.e. a trifid leaf. Here, however, all three lobes are branched, partly at least dichotomously, the middle one most extensively.

Plant F (Fig. 7) has all its leaves of this trifid type, and the branching of each lobe is for the most part monopodial, though a tendency to dichotomy is still observable in some cases. In the weaker fronds of the starved plants mentioned above, this trifid character is the rule; but in one case at least (Fig. 8) there is a clear primary dichotomy with no middle member, and each branch apparently forks again, three of the four resulting members branching monopodially. The stronger fronds of the starved plants are simply feeble expressions of the adult type. (Cf. Fig. 9.)

The adult type of frond in this species is quite unique among the Ferns. 'The long petiole branches to the right and left, giving off lateral members from the upper faces of its two recurved arms in a scorpioid manner' (Seward, '99, p. 175). It is well illustrated by Seward ('99, p. 176, Fig. I). In all the fronds we have ourselves seen there is a middle 'pinna' arising from the angle of the dichotomy. This is commonly the longest of all the pinnae.

The following solution of the problem as to the real nature of this curiously branched frond is suggested. The primary branching of the frond is assumed to be dichotomous. Many of the leaves of the young plants are difficult or impossible to interpret as monopodially branched, and a primary dichotomy appears to be the simplest explanation of the 
main fork in the adult. In the angle of the dichotomy, however, a ' middle lobe' is developed in all but some of the simplest fronds, just as is often the case, for instance, in the branching of the thallus of the Liverworts. It is this middle lobe which gives to so many of the fronds of the young plants their trifoliate character (Figs. 2, 6, and 7). In the adult the middle lobe is represented by the median pinna ${ }^{1}$. The subsequent branching of the primary forks and of the middle lobe at first (i.e. in the young plants) shows a tendency to be dichotomous, but the dichotomous systerns easily pass over into the monopodial type, and the three lobes of the trifoliate leaf are in most cases pinnately branched and correspond with the 'pinnae' of the adult. Some of the starved plants have trifoliate fronds whose three lobes resemble in all respects the 'pinnae' of the adult frond.

The origin of the adult frond from this type of structure is not at first sight quite obvious. We suggest that it arises by the dichotomy of the primary forks and the repeated dichotomy of the lower member only of each successive fork, the upper member in each case, and the lower member also of the last fork, becoming a pinna. If this be so, the 'recurved arm' is a sympodial axis composed of the bases of the lower members of successive dichotomies. To suppose that it is a monopodial axis giving off lateral members from the upper face only would be to assume a type of branching unparalleled, so far as we know, in the fronds of Ferns, while the 'scorpioid' character of each half-frond certainly suggests a sympodium. Furthermore, the hypothesis of dichotomy as the fundamental type of branching in the frond as a whole, enables us to bring it into relation with the fronds of Gleichenia. Many of the species of this genus, as is well known, have long straggling fronds with repeated dichotomous branching. 'Pinnae' may be borne on the primary forks, or may be confined to those of a higher order. A bud normally arises from the angle of the primary dichotomy. This bud is sometimes developed, forming a main rachis of the whole frond, and itself dichotomizing and bearing pinnae to a greater or less extent. Boodle ('01 B, p. 705) has already suggested that it is possible to derive the pinnate type of frond, so common among the Ferns, from such a dichotomous frond as is found in these straggling Gleichenias, by imagining the successive forks of this main rachis to be limited in growth so that they become pinnae. Such a mode of origin is all the more likely since some species

${ }^{1}$ It is possible to regard the 'middle lobe' not as a structure sui generis, so to speak, as it apparently is in the thalloid Liverworts, but rather as in origin the inner branch of the second dichotomy, becoming in the adult a pinna which, like the other inner branches, has lost the power of further dichotomy. Such an interpretation is indeed suggested by Figs. I, 2, and 5, and is perfectly compatible with the structure of the adult frond. No light is thrown upon this question by any of the adult fronds of Gleichenia we have examined (vide infra), though an extended comparative examination of the fronds of young Gleicheniaceous plants might be expected to illuminate the whole subject. 
of Gleichenia, e. g. G. circinata, speluncae, and elongata, exhibit intermediate forms in which the bud of the main rachis grows more strongly than the primary forks, and the successive forkings of the rachis appear as pinnae, while $G$. Boryi actually shows a typical pinnate structure of the whole frond, the main rachis itself ending in a 'pinna.'

We are inclined to regard the frond of Matonia pectinata as having also taken origin from a primitive dichotomous type, but in another direction. The middle lobe or bud in the angle of the primary fork has here been at once limited in growth so that it forms a pinna, while the primary forks dichotomized repeatedly, the upper member of each successive fork forming a pinna, while the lower branched again. Thus the Matoniafrond became moulded into a fan-shaped structure with a power of peripheral growth, while the ordinary Fern-frond acquired a pinnate structure retaining a power of terminal growth. Here again certain species of Gleichenia furnish evidence of intermediate stages in such a process of evolution. G. Alabellata, Br., G. Cunninghami, Hew, and G. quadripartita, Hk., show the relevant phenomena. Seward ('99, p. 192, Fig. 7) has already noticed the 'superficial resemblance' of the frond of $G$. Cunninghami to that of Matonia pectinata. In the frond of the former species which he figures there is no middle bud evident, but the primary forks of the frond (which bear pinnules from their base) fork again close to their base, and each of the four secondary members at once forks again. The three upper members on each side so produced become simple pinnae, undergoing no further branching, but the lowest (peripheral) member on each side dichotomizes once more. This already gives us an indication of what has taken place in Matonia pectinata. G. flabellata sometimes produces fronds (Plate XXXI, Fig. IO) which are even closer to the Matonia-type, for here only the lower members of the secondary forks dichotomize, and the bases of the primary forks are bare of pinnules, while a median bud is present, though it has become adherent to one of the primary forks ${ }^{1}$. If this bud were developed into a pinna (a condition which is sometimes realized in G. cryptocarpa, Hk., though in that species the frond is more complicated and less compact), and the peripheral dichotomizing were carried further, we should have the type of the adult Matonia pectinata. In G. quadripartita, Hk., the arrest of the branching of the frond after the second dichotomy is characteristic, as the specific name indicates, but the lower branch on each side here also sometimes branches again, as in the frond of $G$. flabellata figured.

Fig. 9 shows a frond of Matonia from one of the starved plants alluded to above. The secondary dichotomy has occurred on the left,

1 On the hypothesis suggested in the footnote on p. 479 this middle bud would represent the arrested inner branch of the first dichotomy of the left-hand member of the primary fork. Its position here would then be more primitive than when it oecupies the actual angle of the fork, as in most Gleichenias. 
while on the right there is a suggestion of it, the lowest pinnule on the peripheral side being isolated and much longer than the others.

It seems difficult to resist the conclusion that the adult frond of Matonia pectinata represents a further development of the tendency seen in these Gleichenias with compact flabellate fronds. Though growth in length of the axes of the frond has been arrested, the extent of lamina borne by each frond has been kept, along with the compact habit, by the peripheral growth brought about through the retention of the power of branching of the outer (lower) member of each successive dichotomy.

It is interesting to note that the rachis of each 'pinna' retains at its base the characteristic form of the leaf-trace as it leaves the stele of the rhizome, though without the final curl, while the sympodium formed, on the view just expressed, by the crowded bases of successive members of the dichotomizing system, shows a vascular system consisting of a closed cylinder with an internal band-shaped vascular strand. This partial simulation of the rhizome-type of vascular structure by the sympodium is probably due to the exigencies of the crowded insertion of successive pinna-traces.

The form of the frond in the other species of the genus, $M$. sarmentosa, should be mentioned in this connexion. Here the frond possesses a long unbranched rachis, continuous with the petiole, and bearing distant groups of two, or sometimes three, narrow strap-shaped laminae which reach a length of several inches. The members of each group of laminae are inserted on a slightly swollen common base, from which often arises a structure like an arrested bud. The laminae themselves are often dichotomously branched, and then resemble very closely the dichotomizing laminae of the young $M$. pectinata (e.g. as seen in Plate XXXI, Fig. 6). In the only intact frond we have seen, the rachis also ends in a similar lamina dichotomizing in the same manner.

The type of branching of the frond of $M$. sarmentosa is thus clearly different from, and appears to be as exceptional as, that of $M$. pectinata. Its morphology is puzzling, though it might possibly be elucidated with the help of young plants, which have not yet been seen. The adult frond scarcely gives any help with that of $M$. pectinata, but there is certainly no clear indication of derivation from a typical pinnate form. The resemblance of the dichotomously branched strap-shaped laminae to those of the young $M$. pectinata is very striking ${ }^{1}$.

If the above considerations are sound, it follows that the morphology of the leaf in $M$. pectinata furnishes strong confirmation of the suggested

${ }^{1}$ It is of interest to note that the vascular system of the rhizome of $M$. sarmentosa is organized on the same lines as that of a young $M$. pectinata. Of two fragments which we were able to examine both showed the dicyclic arrangement. In one case the second cylinder was protostelic, in the other solenostelic. In the second case a dorsal gap in the second cylinder was still open. The base of the petiole, however, could not be examined. 
Gleicheniaceous affinities of Matonia, recently expressed by Christ, who includes both in his class Oligangia, as well as by Bower, who places both families in his group of 'Simplices,' and concludes that the affinities of Matonia are with Gleicheniaceae rather than with Cyatheaceae ('00, p. 45). The evidence for this view, which must be based primarily on the sporangial and soral characters, is difficult to impugn, and it seems to us to be strengthened by the morphology of the leaf, which appears to have much in common with the Gleicheniaceous type and nothing with the Cyatheaceous.

\section{Detailed Account of the Progressive Complication in the Vascular System of the Rhizome and Leaf-Trace ${ }^{1}$.}

(I) The six young Plants.

A transverse section of the proximal end of Plant A (Pl. XXXI, Fig. I I) shows a very simple protostele, consisting of about twenty-four elements, surrounded by a pericycle and endodermis which are obviously sister-layers. The whole of the tissue of the stele apparently consists of xylem, which is made up of about ten scalariform tracheids and fourteen parenchymacells, exclusive of the pericycle. No phloem can be distinguished. The cortex is only three or four cells thick.

This structure is maintained for a distance of about $.5 \mathrm{~mm}$., both cortex and stele increasing in diameter, but undergoing no alteration of structure. The cortex then extends itself on the dorsal side of the rhizome preparatory to the origin of the first leaf ${ }^{2}$, while on each side, in connexion with the leaf base, a root is given off. The insertion of the steles of these roots on the stele of the stem takes place in front of (about $.1 \mathrm{~mm}$. nearer the apex of the stem than) the insertion of the leaf-trace.

The leaf-trace itself is of the simplest, consisting merely of a strand of tracheids, which are inserted almost perpendicularly on those of the stemstele, surrounded by pericycle and endodermis, but, like the stele, apparently without phloem. The structure of such an early leaf-trace is in fact indistinguishable, except for its smaller size, from that of the stele of the rhizome. In neither is any trace of spiral elements to be seen.

Immediately in front of the origin of the first leaf-trace and before the insertion of the two root-steles is reached, the stele of the rhizome is found

${ }^{1}$ It has been thought well to publish full details of the phenomena met with during the progressive complication of the vascular system. A shorter and more general account, accompanied by explanatory tables and diagrams, will be found on pp. 496-502.

${ }^{2}$ It is of course possible that earlier leaves originally existed in this, the youngest specimen obtained. No definite indication of approach to the structure of the primary root was observed in the transverse section of the proximal extremity, $.5 \mathrm{~mm}$. below the first leaf; but, on the other hand, the extreme simplicity of the structure of this part of the rhizome and of the leaf-trace indicates that the latter belongs at least to a very early leaf. 
to have increased considerably in diameter, and now possesses some fifty or sixty elements (Fig. I2). In its centre is a group of about half a dozen cells of rather smaller diameter than the tracheids and parenchyma surrounding them, possessing relatively thin walls which stain dark blue with haematoxylin, and no nuclei. This is the first appearance of unmistakable phloem. The cells in question are no doubt sieve-tubes. Associated with the sieve-tubes are an approximately equal number of parenchyma-cells, with nuclei which fill the greater part of the lumina, and dense granular protoplasm (prot. $c$ ?). These are probably the 'Eiweisszellen' of Strasburger, so widely distributed among Pteridophytes in association with sieve-tubes. The first two root-steles have no connexion with the strand of internal phloem. In the neighbourhood of the points of insertion of these steles, however, there are indications of the appearance of external phloem elements at various points on the periphery of the rhizome-stele, and these are connected with the phloem of the root-steles. Just in front of the second of these two roots the rhizome-stele stretches itself at right angles to its axis preparatory to giving off the second leaf-trace, and the internal strand of phloem follows the outline of the stele, and itself sends a contribution to the trace (Fig. I3, int. ph. tr.). The external phloem of the stele, which by this time has become a fairly well-defined layer, also contributes to the trace. The phloem of the leaf-bundle during its passage through the cortex appears to surround the xylem completely, though it is mainly massed on the adaxial side, and consists largely of parenchyma. A third root is inserted just behind and a fourth just in front of the origin of the second leaf-trace. Beyond this point the stele increases greatly in diameter, the central phloem-strand becoming particularly bulky. In the middle of the latter appear certain large, more or less isolated cells, which resemble the cells of the endodermis both in size and contents, and represent the first appearance of an internal endodermis. The stele becomes greatly elongated dorso-ventrally and three roots, which have not yet penetrated the cortex, arise from its ventral side.

The tissue of the dorsal side of the stele now draws together to form the third leaf-trace (Fig. 14), which consists of an arc of xylem incompletely surrounded by phloem, that in the adaxial concavity of the arc derived from the internal phloem of the stele, while the sieve-tubes occurring on the lateral and abaxial faces of the trace are continuous with the external layer of the stelar phloem. The endodermis of the concavity of the trace is also continuous with the internal endodermal cells of the stem-stele. The external phloem of the stele beyond the point of departure of the trace is, of course, continuous with the adaxial phloem of the trace. We have here, in essentials, the relations of external and internal phloem of the stem-stele with leaf-bundle-phloem characteristic of the Lindsaya-type ${ }^{1}$.

1 Tansley and Lulham ('02). 
Another point is to be noted in connexion with the origin of this third leaf-trace. For a distance of . I mm., during the early stages of the separation of the trace, the internal phloem of the stem-stele has a strongly curved form, into the concavity of which the xylem projects on one side of the base of the trace. This is the very simplest form of that 'local dilatation of the edge of the leaf-gap' which, as Gwynne-Vaughan has shown, forms the starting-point of the formation of internal accessory vascular strands.

After the departure of the third leaf we have reached a point in this specimen so close to the apex of the stem that the whole of the tissue on the ventral side of the stele is in a meristematic condition, the xylem on the dorsal side of the central phloem being alone lignified. In the course of the next. $\mathrm{I} \mathrm{mm}$. the whole of this dorsal tissue of the stele, including the central phloem, is seen to be continuous with the fourth leaftrace, while the ventral meristematic tissue ends in the stem-growing point. The actual growing apex is forced downwards by the early differentiation of the fourth leaf, so that it appears as a curved knob of meristematic tissue adhering to the ventral surface of the petiole.

Plant B (Fig. 2) is very slightly more advanced than A. Its tissues were not very well preserved and present no new anatomical feature. The stele of the rhizome shows the same features as in the more advanced part of $\mathrm{A}$, and the leaf-bundles are of corresponding type.

Plant C, as may be seen from Fig. 3, possessed two leaves of considerably greater size and elaboration than those of A and B. A length of rhizome of a little over $\mathrm{I} \mathrm{mm}$. is preserved. The structure of the proximal end is essentially the same as the structure of $B$ and that of the distal end of A, i. e. it consists of a hollow cylinder of xylem, with external phloem, pericycle, and endodermis, and enclosing a central strand of phloem which itself contains more or less connected endodermal cells. Passing forward towards the apex, the internal endodermal cells are continuous with a constant though irregular strand, consisting, on the transverse section, of several cells. The origin of the leaf-traces is, in this specimen, decidedly inconstant and irregular. Sometimes they are attached at right angles to the course of the stem-stele, while in other cases they pass off slowly, so that successive sections of the rhizome cut both stele and trace transversely. This form of variability is common in all the young plants. The cross sections of the different traces also vary considerably in form. The local dilatation of the xylem of the stele on one side of the attachment of the leaf-trace, already described in the case of the third trace of Plant A, occurs again in several of the traces of the present specimen. In one case the dilatation is continued forward as a ridge in front of the separation of the trace for a distance of $.09 \mathrm{~mm}$.; it then becomes separated from the rest of the xylem of the stele and continues for $\cdot 2 \mathrm{~mm}$. as a free strand surrounded by the internal phloem. It becomes gradually thinner, but does 
not die out, and eventually enters into connexion with the dilatation at the base of the next trace. The apex of the rhizome in this specimen had died and its tissues partly perished. A young leaf with undifferentiated tissue and showing its circinate vernation is attached to this portion of the stem.

Plant D (Fig. 4), as will be seen, bears leaves of a type no more complex than those of $C$, nor does its rather bulkier stele show any definite advance in structure. The transverse section of the proximal end shows essentially the same type that we saw in the distal end of C, i.e. the central phloem of the stele encloses both internal endodermal cells and also a free strand of xylem. But here the xylem-strand is comparatively bulky and centrally situated, while the endodermal cells are few and more or less scattered (Plate XXXII, Fig. I5). Presently the endodermal cells unite to form a strand one or two cells thick and crescent-shaped in cross-section on one side of the central xylem, while the latter comes into connexion with the external xylem, probably in the mid-dorsal line. A leaf-trace is now gradually given off on one side of this connexion. The strand of endodermal cells in the concavity of the leaf-trace is perhaps ${ }^{1}$ unconnected with the internal stelar endodermis, but the corresponding phloem is certainly connected both with internal and external stelar phloem. The leaf-trace, after it becomes free from the stele, is concentric in structure. It is kidney-shaped in section and its wings contain large scalariform elements, while its centre is composed of a strand of small tracheids. After the departure of the leaf-trace, there is a gap left in the xylem-ring ${ }^{2}$, and this is closed by the external xylem of the stele, the inner xylem-strand becoming immediately again detached from the outer ring. Later it again enters into connexion with the outer ring, and the next trace arises from the other side of the point of connexion. Though rather bulkier, it arises in identically the same way and has evidently the same structure as the last. The endodermis of its concavity is certainly connected both with the internal and with the external stelar endodermis. Before the trace is fully detached, the tissues of the stele cease to be fully differentiated, and the stele shortly becomes promiscuously invaded by cells like those of the inner cortex, the rest of the stelar cells having meristematic characters. The stele is then lost in a uniform mass of brown cells, while a curved knob of meristematic cells, representing the actual growing point, is found attached to the ventral surface. The explanation of this appearance is probably due to a checking in this particular plant of apical growth beyond the point of insertion of the last leaf, and the consequent passing over of the majority of the undifferentiated cells into a passive condition without differentiation.

1 Owing to defects in the series this point could not be absolutely determined.

${ }^{2}$ Where such a gap occurs it may be called a 'xylem leaf-gap,' or a 'xylem-gap,' as distinguished from a true leaf-gap in which the tissue of the pith is put in connexion with that of the cortex owing to an interruption in all the stelar tissues. 
Plant $\mathrm{E}$ had most of its leaves broken off. The one nearest the apex (Fig. 5) was considerably larger and more complex than any we have yet met.

A transverse section of the proximal end of the rhizome (Fig. 16) shows a state of things rather different from any we have hitherto seen. While in $\mathrm{D}$ there is present an internal endodermis (either in the form of scattered endodermal cells or of a strand having a crescentic section) not associated with ground-tissue-pith ('internal cortex' of Van Tieghem and Jeffrey), together with an internal ridge or strand of xylem, in the present case there is an internal endodermis enclosing a ground-tissue parenchymatous pith of about twenty cells ; we have, in fact, a simple solenostele with a comparatively slight local internal dilatation of the xylem-ring. The first leaf-trace goes off gradually, apparently in the form of a closed cylinder. The pith included within this ring almost certainly communicates with that of the stele, though the connexion was not actually seen. There is no leaf-gap. A group of small tracheids (not spiral) occurs in the middle of the abaxial side of the trace. After the departure of the first trace the internal xylem-dilatation becomes more marked. The second leaf-trace goes off like the first. The connexion of its pith with that of the stele is here indubitable. There is no leaf-gap, but the xylem of the trace is interrupted by the junction of the external with the internal endodermis of the trace, at the point corresponding with the opening in the horseshoe type of trace.

The internal xylem ridge now becomes cut off from the ring by an extension of the internal phloem. It runs past the third node without joining the external xylem. This is the first instance of such a behaviour in this species, a behaviour which is quite exceptional, but which we have found in one case in the relation of the third cylinder to the second in the adult plant ${ }^{1}$. The internal endodermis also extends at the node itself round the internal strand, but immediately afterwards the latter rejoins the external xylem, and at the point of junction tracheids are seen running from the central strand to the point from which the trace has just departed. In the course of the next internode the xylem of the central strand again becomes separated from the external xylem by an extension of the phloem. Soon, however, the junction of the xylem is re-effected, and this is maintained through the fourth node. The fourth leaf-trace goes off similarly to the third. The fifth trace now follows on the other side. It goes off almost perpendicularly to the axis of the stele, is considerably bulkier than the preceding traces, and is the first which makes a definite gap in the stele, so that the ground-tissue of the cortex comes into connexion with that of the pith (Fig. 17). This gap, however, is very short, i. e. it does not extend in front of the base of the leaf-trace (Fig. I8). Immediately after the closure

\footnotetext{
1 Seward ('99), p. 186, also records such a case.
} 
of the gap, tracheids can be seen running upwards and forwards from the internal strand to the point in the external xylem-ring from which that wing of the leaf-trace which is turned towards the mid-dorsal line of the stele has just departed, showing that the internal xylem-strand is acting as a 'faisceau réparateur' (Fig. I9).

In the course of the next internode, which is considerably longer than the last, the internal xylem-strand becomes completely separated from the external xylem by phloem, and eventually by endodermis also (Fig. 20). The sixth trace shows a reversion to the earlier type. It departs very slightly to one side of the dorsal line of the stele and makes no leaf-gap. At its base it has an internal endodermis only, which is in connexion with the dorsal part of the endodermis surrounding the internal strand of the stele, the pith of the stele being still confined to the ventral side of the internal strand. The inner wing of the trace (i. e. next the mid-dorsal line) departs as usual slightly earlier than the outer. Immediately after the separation of the trace, the usual connexion is made between the xylem of the internal strand and the outer xylem.

In the course of the next internode the xylem of the internal strand again becomes separated from the outer xylem, in this case by the phloem alone. The seventh trace also departs without making a gap; it has no pith, but an internal endodermal strand only, connected with that of the stele. The seventh internode is like the sixth and the eighth trace like the seventh. Towards the end of the eighth internode the internal strand becomes again completely separated from the stele by endodermis as well as phloem. At the same time a dilatation of the pith extends dorsally and connects with the pith of the ninth trace, which is however insignificant, and confined to its base. The usual connexion of the xylem of the internal strand with the outer xylem occurs just after the departure of the xylem of the trace.

In the course of the ninth internode the xylem of the internal strand again becomes separated from the external xylem, at first by phloem alone. The endodermal separation is barely made before the internal strand again connects with the external xylem, this time before the departure of the (tenth) trace. This is the first occasion on which the xylem of the internal strand is directly connected by obliquely running tracheids with the xylem of the leaf-trace (Fig. 2I). Just as this xylem-connexion is made two or three phloem-elements appear in the centre of the internal xylem-strand (Fig. 21), and almost immediately become connected laterally with the phloem surrounding the internal strand. This phloem-connexion is widened as the trace departs, so that the internal phloem becomes a branch of the external, and the whole of the dorsal half of the internal xylem-strand helps to fill the gap in the external xylem left by the departure of the trace, while the ventral half continues through the tenth internode separated from the 
outer xylem. Just before the eleventh trace departs the internal strand of xylem again enters into connexion with the outer, just at the point where the dorsally turned wing of the trace is about to separate and appears to close the xylem-gap, as in the case of the preceding trace. A transverse section of the trace close to its point of origin is represented in Fig. 22.

The twelfth trace is considerably bulkier, and a considerable gap occurs in the side of the stele, placing the pith of the stele in connexion with the cortex. This gap, however, opens before the departure of the trace and is not actually made by the latter, the xylem immediately dorsal to the gap not departing with the trace, but remaining behind in the stele. The xylem of the internal strand also enters into connexion with the external xylem on the opposite side to the gap, but does not directly contribute to the trace. As the second (ventrally turned) wing of the trace is departing, the internal xylem-strand loses its first connexion and makes a new one with the external at the point from which the first (dorsally turned) wing has gone off, the tracheids again running up into the external xylem and taking part in the closure of the xylem-gap (to be distinguished from the lateral gap in the stele as a whole, which is quite an exceptional phenomenon).

In the course of the twelfth internode the xylem of the internal strand becomes, as usual, separated from the external by phloem, but for a very short space. It becomes reconnected again considerably before the departure of the thirteenth trace. The stele has not only increased considerably in diameter, but also in xylem-elements in proportion to its bulk, so that the pith is reduced in one place to three or four cells. The latter rapidly increases again, however, at the expense of the internal xylem-strand, so that from a crescentic cross-section it acquires a triangular and then a circular one, the internal xylem-strand completely disappearing. The thirteenth trace now arises from a diametrically opposite position on the stele to that at which the internal strand has been absorbed. The trace goes off as usual with one wing slightly in advance of the other. It has a small pith and is distinctly less bulky than the immediately preceding traces. Its departure makes no gap in the xylem of the stele. This trace then shows a striking reversion to the state of things existing at the proximal end of the plant under description.

As a preliminary to the origin of the fourteenth trace, a new local dilatation arises on the inside of the xylem. The trace departs much like the last and the tracheids run from the new internal strand to the point of departure of its second wing. The tissues now begin to show the same appearance that was noted at the apex of $\mathrm{D}$ and the growing point is reached.

The most advanced $(\mathrm{F})$ of the six young plants available (Plate XXXI, 
Fig. 7) has at its proximal end a structure practically identical with that seen in the neighbourhood of the tenth trace of $\mathrm{E}$, i. e. an internal xylem-strand enclosing a few phloem-cells in its midst, and separated from the xylem of the stele by phloem, endodermis, and pericycle. The first trace is bulky and its base occupies nearly the whole of the dorsal surface of the stele, but it goes off in the usual way with one wing distinctly in advance of the other. Before either wing has become separated from the stele, however, the xylem of the internal strand comes into connexion with external xylem, and tracheids are seen in abundance running up towards the bases of the xylem-wings of the trace. The trace is distinctly horseshoe-shaped; its pith, directly it becomes free from the stele, coming into connexion with the cortex of the stem, so that the latter is in connexion with the pith of the stele through the pith of the trace. In the course of the next internode the internal strand of phloem comes into connexion with and is absorbed in the external, and at the same time the internal strand becomes shut off from the stele by endodermis. This separation persists considerably longer than in Plant E.

The second trace arises like the first, the xylem of the inner strand again coming into connexion with the outer xylem while the trace is departing. It is again distinctly horseshoe-shaped in section, and maintains this shape in the petiole. During the origin of the trace a new strand of phloem arises in the centre of the xylem of the internal strand, but dies out again very shortly.

There is no need to describe in detail the origin of the whole of the twelve traces of this plant, since they all arise in fundamentally the same way. It is to be noted, however, that as in the advanced traces IO, II, and 12 of Plant E, the bulkier leaf-traces here take off so much of the dorsal side of the stelar xylem that the internal strand actually fills, or helps to fill, the gap thus made in the external xylem, whereas in the earlier type of origin the gap is closed by the external xylem itself, the internal xylem merely coming into connexion with the external laterally to the point of closure ${ }^{1}$.

The complete separation of the internal strand, which we may now call the second cylinder, takes place regularly after the departure of the leaftrace, and is maintained throughout the internode. Pith as well as endodermis often extends right round this second cylinder. The first indication of the origin of a leaf-trace is the thickening of the pith dorsal to the second cylinder, and the correlated pushing out of the xylem-ring on that side; the thickened region of pith now becomes disconnected from the rest on the side towards the mid-dorsal line, causing the second (inner) cylinder to become confluent with the outer one, first by its phloem and then by its

1 It is to be understood that usually no actual xylem-gap is formed in either case, the tracheids of the internal strand moving up pari passu with the moving out of the leaf-trace tracheids. 
xylem. Soon after this the first arm of the trace (turned towards the middorsal line of the stele) departs, and meanwhile the thickened portion of the pith disconnects with the rest on the outer side and becomes the pith of the leaf-trace, the xylem of the inner cylinder becoming confluent with that of the outer immediately below the base of the outer arm of the trace. This outer arm of the trace now departs and the trace-pith is opened to the cortex of the stem. Shortly afterwards the inner cylinder again separates from the outer.

After the departure of the fourth trace, the strand of phloem in the centre of the second (inner) cylinder becomes constant, and increases in size, being sometimes isolated and sometimes in connexion with the external phloem of the second cylinder. In the course of the seventh internode a strand of endodermal cells appears in the midst of this internal phloem, but disappears again before the departure of the next leaf-trace. The eighth trace is the first in this plant showing a true 'leaf-gap' in a single transverse section, i. e. the pith of the base of the trace opening to the cortex before it is disconnected from the pith of the stele (Pl. XXXIII, Figs. 27, 28 right). Before the eighth node is passed another endodermal rod appears in the internal phloem, consisting this time of but a single cell in cross-section. It dies out again almost at once. The ninth trace shows a reversion to an earlier type, passing off much more suddenly and showing no gap, while the xylem of the inner cylinder joins that of the outer between the bases of the arms of the trace (Pl. XXXIII, Fig. 28 left). The tenth internode shows a third endodermal rod, which rapidly increases in size, joining the outer endodermis of the inner cylinder, and then disappears again. The eleventh internode shows yet another, which persists through the rest of the stem.

\section{(2) Starved Intermediate Plants.}

The next advance in complexity we found in certain plants, already alluded to, which were growing in a deeply shaded crevice below an overhanging rock close to the top of Gunong Ledang. The smallest of these scarcely exceeded $\mathrm{F}$ in stoutness of rhizome or size and complexity of leaf, though they have longer petioles; while others are considerably larger, though in all respects much smaller than typical vigorous plants growing in the open. They were, no doubt, plants of some age which had been unable to attain anything like their full growth, owing to want of soil and light. Their vascular structure is of interest, since it leads up from that of the six young plants to that of the typical adults.

In the simplest one, which we wiil call for convenience $G$, the stelar system of the rhizome is identical with that of the distal part of $F$, i. e. it consists of an outer solenostele and an inner cylinder, the xylem 
of which is sometimes solid and sometimes in the Lindsaya-phase, with occasionally an endodermal rod enclosed in the central phloem. The leaf-trace at a short distance from its origin shows in cross-section the form of a flat-topped arch (Fig. 23) with the free edges of the xylem sometimes merely thickened and sometimes with an incurved hook structure, which has been recently shown to be very common in the petioles of Ferns with a comparatively simple vascular structure ${ }^{1}$. The free edges of the arch are approximated, and the cavity of the arch is occupied by ground-tissue in continuity with that of the petiolar cortex by an isthmus passing between the free edges. The whole structure is much like that of Gleichenia, $\S$ Mertensia, and even more closely resembles that of Loxsoma ${ }^{2}$.

The behaviour of the inner cylinder at the nodes is the same, in essentials, as in the plant F, i. e. it becomes attached to the outer cylinder dorsally towards the end of the node, just before the end of the departure of the wings of the leaf-trace. When the leaf-trace departs symmetrically the inner cylinder sends up a broad column between the bases of the arms, closing the gap in the outer cylinder and at the same time contributing a strand of tracheids to the thickened end of the leaf-trace arm on each side. Immediately after the closure of the gap, the inner cylinder again becomes free, its internal phloem and endodermis (where present) remaining unaffected throughout the node. When the leaf-trace departs to one side of the dorsal line and asymmetrically, i.e. with the dorsal arm leaving before the lateral one, the connexion of the inner cylinder with the outer takes place below the dorsal arm, before the closure of the gap. In some cases the junction only takes place (just as is normally the case in many of the nodes already described in the young plants) after the departure of the leaf-trace is completed. It might be thought that in such a case the function of the inner cylinder was confined to closing the leaf-gap, as it undoubtedly is in many of the nodes of the younger plants, but in this case an actual continuity can be traced between the tracheids coming up from the inner cylinder, backwards through the thickened edges of the gap, and up the edges of the leaf-trace arms. This backwardly running supply of the incurved arms of the trace is, as we shall presently see, much more extensively developed in the more complex types.

The next stage of complexity is to be found in one of the 'starved' plants $(\mathrm{H})$, with larger, stouter leaves, a rhizome of $2 \mathrm{~mm}$. and an outer stele of I $\mathrm{mm}$. diameter-a considerably larger plant than G.

The inner cylinder is here solenostelic, or sometimes, after the departure

1 Cf. Boodle ('0 1 B), Pl. XXXVIII, Fig. 7; ('01 A), Pl. XX, Fig. I7, Pl. XXI, Fig. 44. GwynneVaughan ('03), Pl. XXXIV, Fig. 25, Pl. XXXV, Fig. 26.

2 Gwynne-Vaughan ('01). 
of the compensation-strand, it forms a gutter, open on the dorsal side, which does not close for some time. The leaf-trace close to its origin is an arch whose ends are curved inwards and then backwards towards the general curve of the arch. The whole thickness of the arch is involved in this curvature, so that the filling of ground tissue extends into the lateral concavities. The cross-section of the trace is very much like that of the solenostelic species of Gleichenia $(G$. pectinata) as figured by Boodle ${ }^{1}$.

The connexion of the inner cylinder with the outer at the node takes place as before towards the end of the node, just as the extremities of the wings are departing. Tracheids from the inner cylinder supply the whole of the backwardly directed limbs of the leaf-trace, and also of course fill up the dorsal gap in the outer cylinder formed by the departure of the trace. As in the simpler case just described, when the trace is asymmetrical, i.e. turned slightly towards the median dorsal line of the stele, the connexion is first made below that wing (the dorsal one) which goes off first.

\section{(3) The adult plants.}

We now come to the 'adult' plants, with steles varying from 5.2 to $\mathrm{I} .6 \mathrm{~mm}$. in diameter. The term 'adult' may be considered ambiguous in a case like this, where the degree of complication attained varies within such wide limits, and is no doubt wholly determined by external conditions. The term may, however, be fairly applied to plants with leaves and leaf-bundles showing their full complication, i.e. in which the forwardly directed limbs of the lateral loops are present (Seward, '99, Plate XIX, Fig. $3^{\mathrm{r}}, \& \mathrm{c}$.).

The complication of the vascular system of the rhizome varies, however, from the case in which there are two siphonostelic cylinders only (Seward, '99), through various cases marked by increasing complexity of the third cylinder, to the case in which there are three complete siphonostelic cylinders (Wigglesworth, '02). This increasing complication is pretty strictly correlated with the diameter of the rhizome, which also determines the diameter of the outer cylinder and that of the leaf-trace. In the large leaf-traces the lateral loops are much more extensively developed than in the smaller ones, and it is this last feature no doubt which is connected with the increased complexity of the vascular system of the rhizome.

The 'adult' rhizomes may be divided into two groups. First, those in which the connexion of the second cylinder with the first occurs relatively far back in the node, just below the point at which the backward curl

${ }^{1}$ Boodle ('01 B), Figs. 26, 27. 
passes into the forward. In this group the connexion takes place by the more or less sudden passing up of a column of tissue from the second cylinder to this point. Secondly, those in which the connexion takes place further forward, sometimes after the complete departure of the trace. In this group the connexion occurs by the gradual raising of the roof of the second cylinder till its sides come into contact with the bases of the backward curls of the leaf-trace.

The first type of connexion between the rhizome cylinders and the petiolar bundle in 'adult' plants is found, as might be expected, in the smaller dicyclic forms. It is essentially similar to cases $G$ and $H$. In the simplest case of this group (Stage $\mathrm{X}$ ) the final 'forward curl' of the leaf-bundle is not continued down to its actual insertion on the rhizome stele, and, as in the last-described case, the second cylinder merely sends up a column of tissue (median, or first on one side, according as the trace is attached symmetrically or asymmetrically) to supply the backwardly directed limbs of the trace and to fill the gap ${ }^{1}$. The tracheids at the outer limits of this column, on each side, sometimes end in a kind of notch (equivalent to the 'gutter' in more advanced forms), which is continuous above with the forward curl of the trace.

In the next case (Stage XI) the forward curl of the leaf-bundle is continued down to the point of attachment, and then the ascending column of tissue from the second cylinder branches on each side into an inner and an outer limb, supplying respectively the backward and the forward curl of the trace (Plate XXXIII, Fig. 29).

The three cases of this group are found in quite small rhizomes, with an outer cylinder of $2.1 \mathrm{~mm}$. average diameter and an inner of $.8 \mathrm{~mm}$.

The second group of cases (Stage XII) represents the great majority of the adult rhizomes. It numbers forty-four nodes, and the outer vascular cylinder has an average diameter of $3.7 \mathrm{~mm}$. A third cylinder occurs in forty-two out of the forty-four cases. The cylinders are much further apart in this group than in the preceding one. Consequently the connexion of the second cylinder, owing to the gradual raising of its roof, with the first, takes place much further forward, often in front of the anterior roots of the leaf-trace ; and the tracheal supply from the second cylinder to the leaf-trace is consequently directed sideways (or even backwards) and upwards instead of forwards and upwards. A final elaboration of the leaf-trace connexions must now be mentioned. The bases of the free forward curls of the trace are continued forwards as outwardly turned

1 The mode of connexion between the second cylinder and the lateral loops of the leaf-trace is decidedly variable in this type. In one case, for instance, the second cylinder sends up a mass of tissue in the form of two arms which pass back and join together to form a median bulge in connexion with the lateral loops of the trace; this then passes forward again, still in connexion with the loops, but above the original arms, and finally becomes the compensation-tongue which closes the gap in the outer cylinder. 
gutters (hooks in vertical section of the node) attached to the bases of the backward curls. After the backward curls have become continuous with the compensation-tongue (roof of the second cylinder) and the gap is formed in the second cylinder, the outer limbs of these gutters are left attached to the free edges of this gap, and are continued forward for some distance as flanges, ultimately dying away before the gap in the second

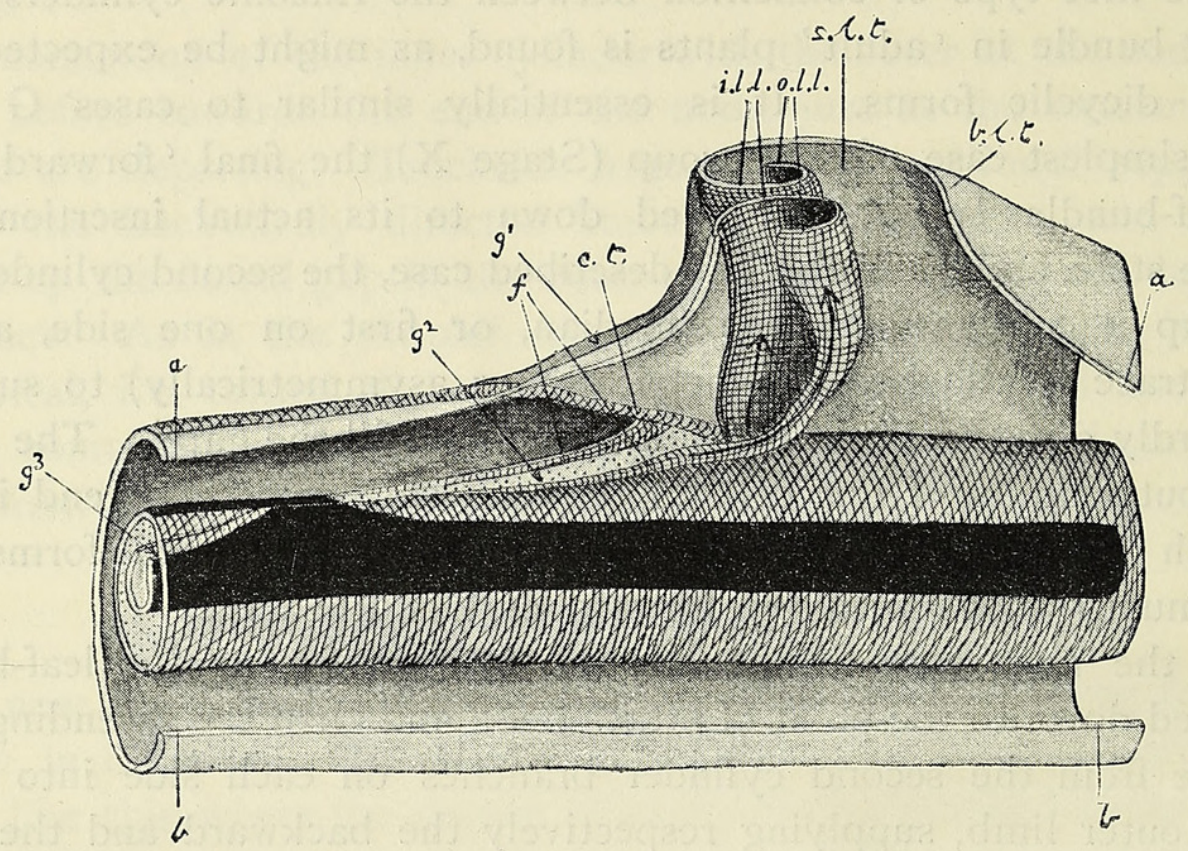

FIG. II. Side view of vascular system of node of large tricyclic form. The side of the outer (first) cylinder and base of the leaf-trace towards the observer is cut away, exposing the left lateral loop of the leaf-trace. Outer cylinder with uniform shading. Middle cylinder together with lateral loops of leaf-trace, compensation-tongue, and mid-dorsal strip of onter cylinder in front of node, i. e. parts supplied from middle cylinder, cross-hatched outside, dotted inside. Inner cylinder with mid-dorsal strip of middle cylinder in front of node, black outside, white inside. The middle cylinder is represented as if transparent, so that inner cylinder is seen through it. $a-a$. upper cut edge, $b-b$. lower cut edge of outer cylinder. b.l.t. back, s.l.t. side of main arch of leaf-trace; i.l.l. inner limbs, o.l.l. outer limbs of lateral loops of leaf-trace; $f$. flanges on edges of gap in middle cylinder, forming the forward continuations of $o . l . l . ;$ c.t. compensation-tongue passing upwards and forwards from middle cylinder attached to bases of lateral loops, and behind cut edge of outer cylinder, to fo: $\mathrm{m}$ mid-dorsal strip of outer cylinder; $g^{1}, g^{2}, g^{3}$, gaps in outer, middle, and inner cylinders respectively. The arrows indicate the direction of the protoxylem-channels of the left lateral loop.

cylinder is closed (Plate XXXIII, Figs. 30,3 I, and Text-Fig. II). A study of the course of the tracheids shows that they run up from the side of the second stele and back along these flanges into the forward curls of the trace, while the existence of continuous protoxylems in these flanges and gutters (p. 508) shows that this water-channel is laid down early, and is presumably well established and important in the economy of this most complicated type of vascular system.

Again, the leaf-gap (i. e. the space between the backward curls of the trace) is considerably wider, and hence the gap left in the second 
cylinder is much wider also. The third cylinder is developed in connexion with the closure of this second gap, which takes place well in front of the node ${ }^{1}$. Of forty-two cases in which a third cylinder occurred, only six cases of discontinuity were found. In the first of these cases the third cylinder arises as an internal thickening of the mid-dorsal region of the second cylinder, immediately after the closure of the gap. Traced forwards it soon becomes detached as a protostelic strand which quickly dwindles and dies out in the ground-tissue. A little further forward in the same internode a third cylinder again arises as an internal thickening of the same region, but a little to one side of the mid-dorsal line. It becomes free and remains so to the end of the series. The third case in another rhizome was exactly like the first. In the fourth case, after passing through a node, and coming into connexion with the second cylinder at the closure of its gap, the third strand separated again, dwindled and died out, appearing again after the next node by a dorsal thickening of the second. The fifth and sixth cases were connected with the branching of the rhizome; at the origin of the weaker branch the third cylinder, formed from the branching of that of the parent axis, died out, but shortly afterwards a fresh one arose freely in the pith. In all these cases of discontinuity the third cylinder is protostelic in structure. In nineteen cases the third cylinder remains attached to the second, as an internal ridge, for some distance in front of the connexion. In all of these also the third cylinder is protostelic. So far as they go, the cases just cited tend to support the view that the third cylinder of Matonia is in its origin an internal elaboration of the gap formed in the second, that it bears in fact the same relation to the second as the second does to the original stele. The blind ending of the third cylinder is not without parallel in other Ferns possessing internal accessory vascular strands. It occurs, for instance, in the young plants of Alsophila excelsa and in Cyathea ${ }^{2}$.

We found twenty-two cases altogether in which the third cylinder is protostelic in structure, four in which it exhibits, for part of its course at least, the Lindsaya-type, and fourteen in which it is solenostelic. Its structure frequently varies in a single rhizome from one of these types to another, the complexity being greatest in the region of the node. Thus in one case the third cylinder is protostelic as far as the node, in the course of which phloem appears in the middle of the xylem. In front of the node its structure becomes solenostelic, and finally, before its junction with the edge of the gap of the second cylinder, it opens and becomes protostelic again, though it has enlarged considerably in the course of these changes. The following table will show the close relation

1 Seward ('99), p. I87.

2 Gwynne-Vaughan ('03). 
of the complexity of structure of the third cylinder with the diameter of the whole vascular system :--

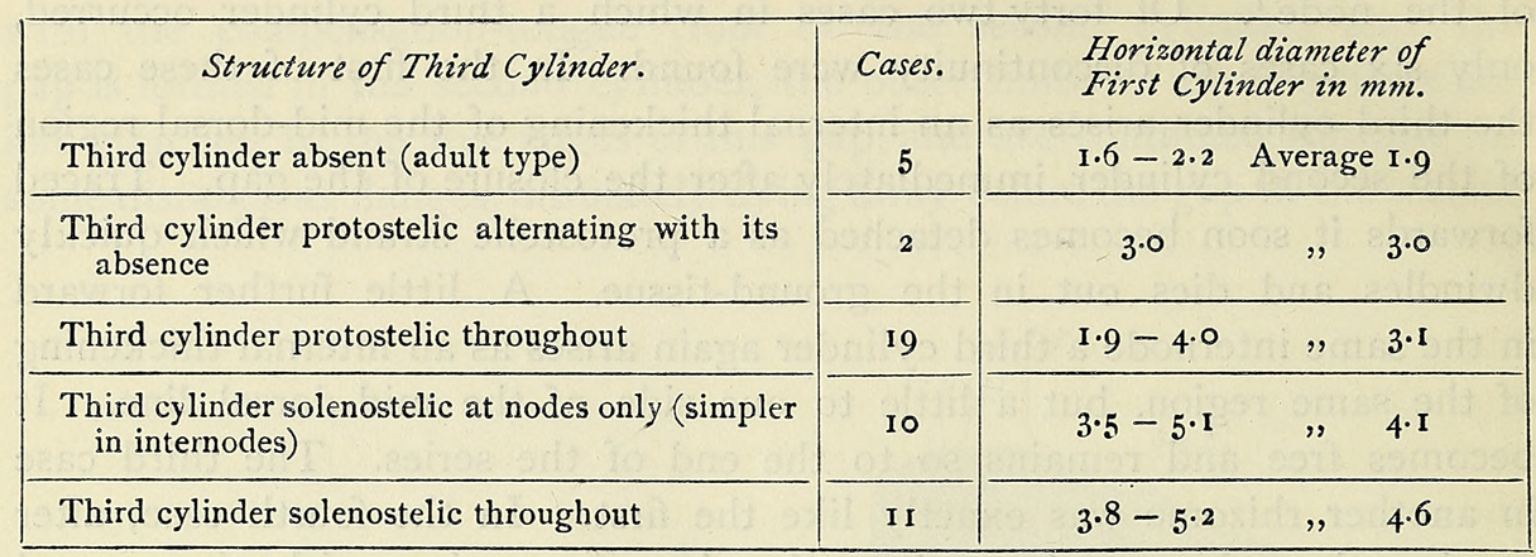

\section{Summary of the Progressive Complication in the Vascular System of Rhizome and Leaf-Trace.}

The following paragraphs summarize the preceding section. The successive complications in the structure of the vascular system are treated as forming a single series with the exceptions noted in the course of the summary; they are illustrated by the accompanying tables (pp. 498-501).

The simplest structure available consists of a slender cylinder of xylem surrounded by pericycle and endodermis, with no characteristic phloem present. The first leaf-trace is a strand of similar structure. The stele of the rhizome now increases considerably in diameter and in number of elements, and a well-marked strand of phloem containing sieve-tubes and parenchyma appears in its midst. Immediately afterwards external phloem appears at several points on the periphery of the xylem, and is connected with the phloem of the first roots, which arise in this region. The second leaf-trace consists of a slender strand of xylem surrounded by a thin layer of phloem, which is contributed to by both the internal and the external phloem of the stele. The internal phloem now increases considerably in bulk, and there arise in it a few large isolated endodermal cells. The third leaf-trace is an arc of xylem covered with a layer of phloem, of which that on the abaxial and lateral faces is continuous with the external, and that on the adaxial concavity with the internal phloem of the stele, while the adaxial endodermis of the trace is continuous with the internal endodermal cells of the stele. An internal ridge of the xylem projects into the internal phloem of the stele on one side of the base of the third trace. The internal endodermal cells eventually join to form a continuous endodermal strand. At subsequent nodes the internal ridge of xylem again appears, and at length a node is reached in which the ridge is continued forward in front of the departure of the trace for a short distance, and then becomes free in the internal 
phloem. Traced forward towards the next node it becomes gradually thinner, but eventually connects with the xylem-dilatation of the next node.

In subsequent internodes there may be a free internal strand of xylem, which is relatively bulky and centrally situated, while the internal endodermis, at first still occasionally represented merely by isolated cells, comes to have the form of a strand, crescentic in cross-section and one or two cells thick, on one side of the internal xylem-strand. The leaftraces are now concentric in structure and kidney-shaped in cross-section. The xylem consists of a central strand of narrow tracheids (probably representing the protoxylem) and two wings of wider scalariform tracheids. The free internal xylem-strand enters into connexion with the external xylem-ring in the mid-dorsal line, in the neighbourhood of the node, sometimes before, sometimes during, and sometimes just after the departure of the leaf-trace, and may remain in connexion with it for the greater part (rarely the whole) of the internode. Where a 'xylem-gap' is formed by the departure of the trace, this is not closed by the internal strand, but by the approximation of the free edges of the external xylem. Tracheids from the internal strand never, at this stage, contribute to the leaf-trace.

The stele increases in diameter and a pith appears, enclosed within the internal endodermis, and consisting of cells like those of the inner cortex. The leaf-traces now often have the form of a closed ring, enclosing a pith which is sometimes, but not always, connected with the pith of the stele at the node. On the adaxial side of the trace the xylem of the ring is not continuous, the space between the free xylem-edges being occupied by phloem or pericycle, or by infolded endodermis.

The internal xylem-strand still varies in its behaviour (in one case running freely past the node without making any connexion with the external xylem), but it is now normally, though by no means invariably, separated from the external xylem during the greater part of the internode, either by phloem only or also by endodermis, and sometimes makes its connexion only at the very end of the node. Tracheids often run from the internal strand to the point in the external xylem from which the last tracheids of the trace depart, but do not contribute to the trace itself.

True leaf-gaps now appear for the first time in connexion with traces, having a horseshoe-shaped cross-section, but they are very short, not extending in front of the actual base of the trace ${ }^{1}$.

Phloem extends from one side into the middle of the internal xylemstrand, and the dorsal half of the strand, above this phloem, frequently moves up and actually helps to close the xylem leaf-gap. Further on another internal phloem-strand appears, and this internal phloem shortly becomes

\footnotetext{
1 Reversions to earlier types of trace without leaf-gaps are common at this stage.
} 


\section{TABLE SHOWING THE DIFFERENT STAGES OF PROGRESSIVE COMPLICATION IN THE RHIZOME AND LEAF-TRACE.}

(I) The young plants.

\begin{tabular}{|c|c|c|c|c|}
\hline \multirow{2}{*}{ Stage. } & \multirow{2}{*}{$\begin{array}{l}\text { Plants } \\
\text { in which } \\
\text { it occurs. }\end{array}$} & \multicolumn{2}{|c|}{ Rhizome. } & \multirow{2}{*}{ Leaf-trace. } \\
\hline & & Internode. & Node. & \\
\hline I. & $\begin{array}{c}\text { A, } \\
\text { node I. }\end{array}$ & $\begin{array}{l}\text { Protostelic structure; no } \\
\text { distinguishable phloem. }\end{array}$ & As in internode. & $\begin{array}{l}\text { Simple, like stele of } \\
\text { stem. }\end{array}$ \\
\hline II. & $\begin{array}{c}\text { A, } \\
\text { node } 2 .\end{array}$ & Lindsaya-type. & $\begin{array}{l}\text { Internal and external } \\
\text { phloem in continuity. }\end{array}$ & $\begin{array}{l}\text { 'Concentric'; phloem } \\
\text { mainly adaxial. }\end{array}$ \\
\hline III. & $\begin{array}{c}\text { A, } \\
\text { node } 3 . \\
\text { B. }\end{array}$ & $\begin{array}{l}\text { Lindsaya-type, with scat- } \\
\text { tered endodermal cells } \\
\text { in internal phloem. }\end{array}$ & $\begin{array}{l}\text { As in II, with local } \\
\text { thickening of edge of } \\
\text { 'xylem-gap.' }\end{array}$ & $\begin{array}{l}\text { 'Concentric'; gutter- } \\
\text { shaped strand. }\end{array}$ \\
\hline IV. & D. & $\begin{array}{l}\text { Lindsaya-type, with in- } \\
\text { ternal (often scattered) } \\
\text { endodermis, and free in- } \\
\text { ternal xylem-strand. }\end{array}$ & $\begin{array}{l}\text { Internal xylem - strand } \\
\text { joining external xylem. }\end{array}$ & $\begin{array}{l}\text { 'Concentric'; kidney- } \\
\text { shaped strand. }\end{array}$ \\
\hline V. & $\begin{array}{c}\text { E, } \\
\text { nodes I, } 2 .\end{array}$ & $\begin{array}{l}\text { Solenostele with local } \\
\text { internal dilatation. }\end{array}$ & As in internode. & $\begin{array}{l}\text { Closed ring in cross-sec- } \\
\text { tion, with sclerized pith. }\end{array}$ \\
\hline VI. & $\begin{array}{l}\text { E, } \\
\text { nodes } 3^{-} \\
9 \text {, and } \\
\text { I3-I4. }\end{array}$ & $\begin{array}{l}\text { Solenostele with internal } \\
\text { xylem-strand often free } \\
\text { (separated from external } \\
\text { xylem by phloem and } \\
\text { also often by endoder- } \\
\text { mis) = second cylinder. }\end{array}$ & $\begin{array}{l}\text { Internal strand in con- } \\
\text { nexion with external } \\
\text { xylem at node. True } \\
\text { leaf-gap sometimes pre- } \\
\text { sent (diagram). }\end{array}$ & $\begin{array}{l}\text { Variable in structure. } \\
\text { Sometimes a closed ring } \\
\text { with sclerized pith, with } \\
\text { or without internal } \\
\text { endodermis, and xylem } \\
\text { interrupted on adaxial } \\
\text { side; sometimes cres- } \\
\text { centic in section. }\end{array}$ \\
\hline VII. & $\begin{array}{l}\text { E, nodes } \\
\text { IO-I } 2 . \\
\text { F (I0 } \\
\text { nodes). }\end{array}$ & $\begin{array}{l}\text { As in VI, but with local } \\
\text { internal phloem and } \\
\text { sometimes endodermis } \\
\text { in second cylinder. }\end{array}$ & $\begin{array}{l}\text { True leaf-gap constant; } \\
\text { dorsal half of second } \\
\text { cylinder often fills gap } \\
\text { caused by departure of } \\
\text { trace (diagram). }\end{array}$ & $\begin{array}{l}\text { Horseshoe-shaped in } \\
\text { cross-section. }\end{array}$ \\
\hline
\end{tabular}


DIAGRAMS SHOWING THE DIFFERENT STAGES OF PROGRESSIVE COMPLICATION BY TRANSVERSE SECTIONS OF CORRESPONDING NODES, INTERNODES, AND LEAF-TRACES. [The diagrams represent actual sections $\times 45$.]

(I) The young plants.

Internode.

:
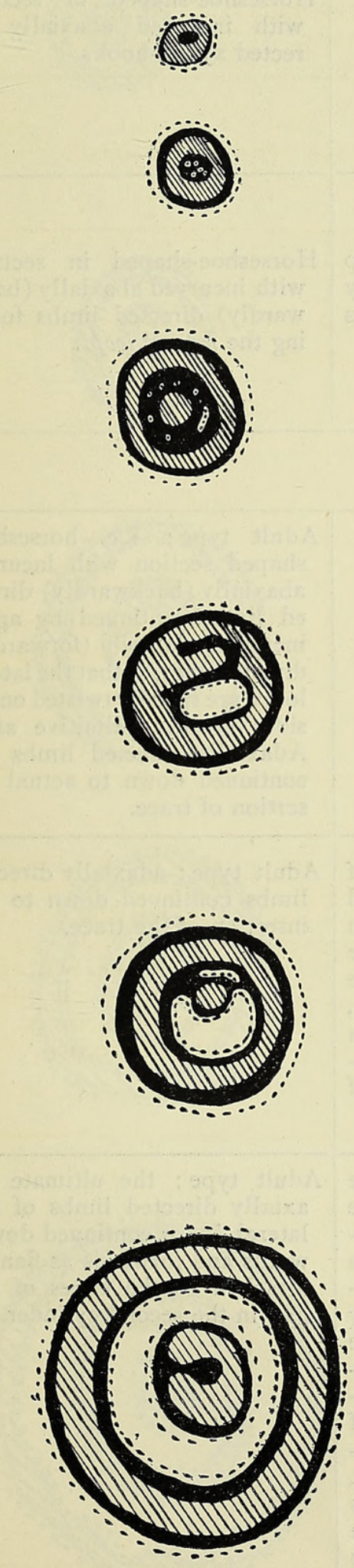

Node.
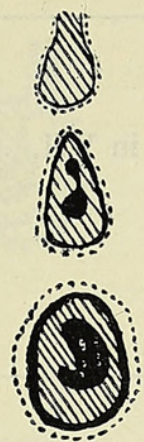

(1):
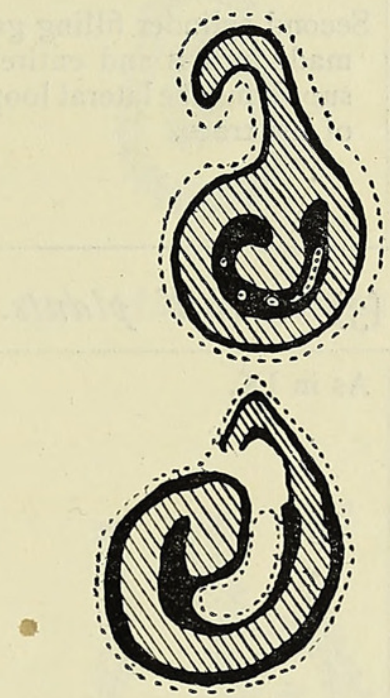

An:

खे
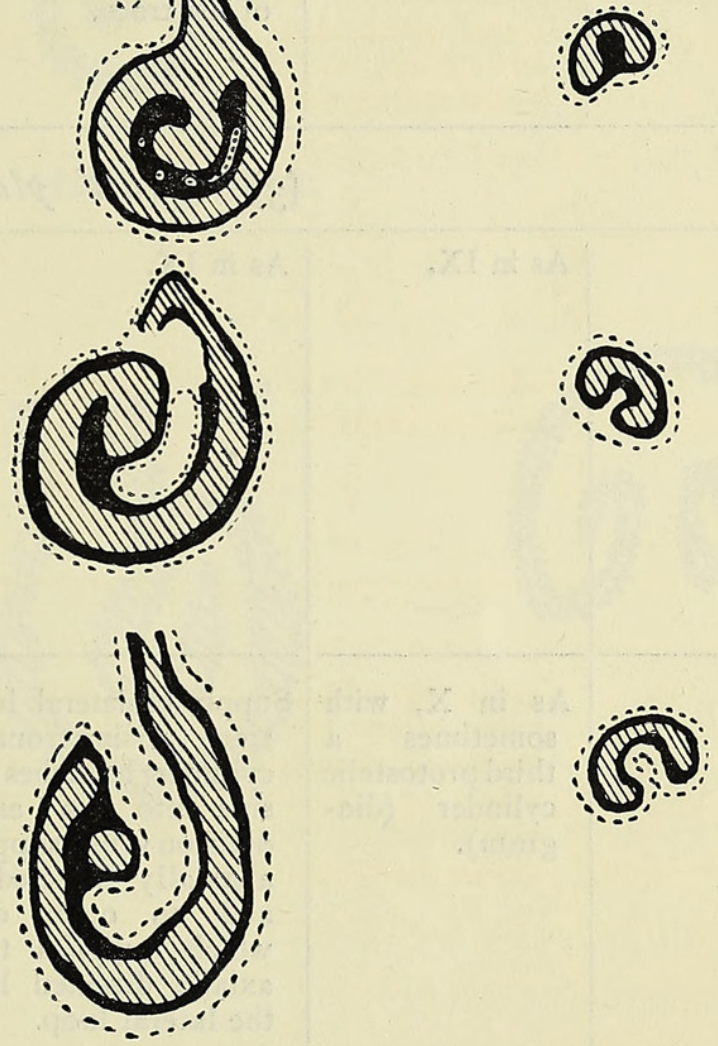
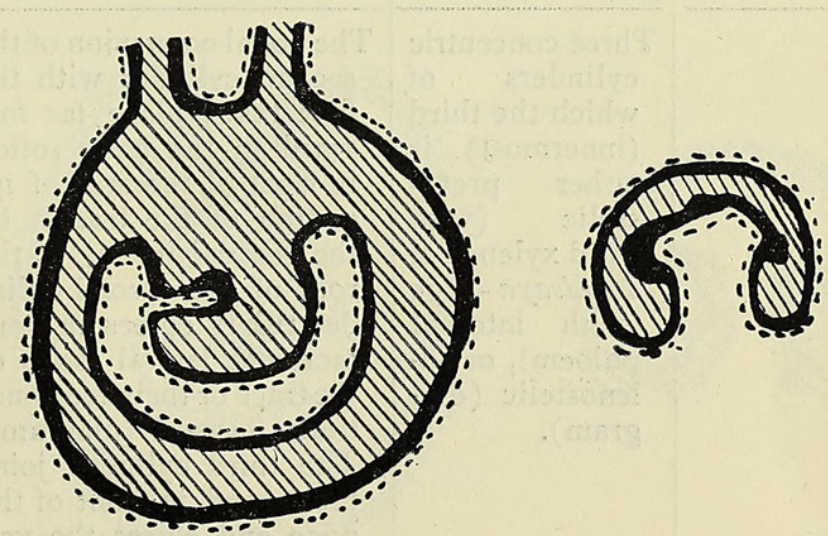

FIG. I 2. Xylem diagonally lined, Phloem black, Endodermis dotted. 
TABLE SHOWING THE DIFFERENT STAGES OF PROGRESSIVE COMPLICATION

IN THE RHIZOME AND LEAF-TRACE (continued).

(2) Starved intermediate plants.

\begin{tabular}{|c|c|c|c|c|}
\hline \multirow{2}{*}{ Stage. } & \multirow{2}{*}{$\begin{array}{l}\text { Plants } \\
\text { in which } \\
\text { it occurs. }\end{array}$} & \multicolumn{2}{|r|}{ Rhizome. } & \multirow{2}{*}{ Leaf-trace. } \\
\hline & & Internode. & Node. & \\
\hline VIII. & G. & $\begin{array}{l}\text { As in VII : but } \\
\text { internal phloem } \\
\text { of second cylin- } \\
\text { der constant. }\end{array}$ & As in VII. & $\begin{array}{l}\text { Horseshoe-shaped in section, } \\
\text { with incurved abaxially di- } \\
\text { rected xylem-hooks. }\end{array}$ \\
\hline IX. & H. & $\begin{array}{l}\text { Second cylinder } \\
\text { solenostelic. }\end{array}$ & $\begin{array}{l}\text { Second cylinder filling gap } \\
\text { made in first and entirely } \\
\text { supplying the lateral loops } \\
\text { of the trace. }\end{array}$ & $\begin{array}{l}\text { Horseshoe-shaped in section, } \\
\text { with incurved abaxially (back- } \\
\text { wardly) directed limbs form- } \\
\text { ing the lateral loops. }\end{array}$ \\
\hline
\end{tabular}

(3) 'Adult' plants.

\begin{tabular}{|c|c|c|c|}
\hline $\mathrm{X}$. & As in IX. & As in IX. & $\begin{array}{l}\text { Adult type; i. e. horseshoe- } \\
\text { shaped section with incurved } \\
\text { abaxially (backwardly) direct- } \\
\text { ed limbs continued by again } \\
\text { incurved adaxially (forwardly) } \\
\text { directed ones, so that the lateral } \\
\text { loops are spirally twisted on the } \\
\text { sides of the primitive arch. } \\
\text { Adaxially directed limbs not } \\
\text { continued down to actual in- } \\
\text { sertion of trace. }\end{array}$ \\
\hline XI. & $\begin{array}{l}\text { As in } \mathrm{X} \text {, with } \\
\text { sometimes a } \\
\text { third protostelic } \\
\text { cylinder (dia- } \\
\text { gram). }\end{array}$ & $\begin{array}{l}\text { Supply of lateral loops of } \\
\text { trace (arising from second } \\
\text { cylinder) branches on each } \\
\text { side into two; an inner } \\
\text { division which suppliesthe } \\
\text { abaxially directed limb, } \\
\text { and an outer division } \\
\text { which supplies the ad- } \\
\text { axially directed limb of } \\
\text { the lateral loop. }\end{array}$ & $\begin{array}{l}\text { Adult type ; adaxially directed } \\
\text { limbs continued down to the } \\
\text { insertion of the trace. }\end{array}$ \\
\hline XII. & $\begin{array}{l}\text { Three concentric } \\
\text { cylinders of } \\
\text { which the third } \\
\text { (innermost) is } \\
\text { either proto- } \\
\text { stelic (with } \\
\text { solid xylem), of } \\
\text { Lindsaya-type } \\
\text { (with internal } \\
\text { phloem), or so- } \\
\text { lenostelic (dia- } \\
\text { gram). }\end{array}$ & $\begin{array}{l}\text { The nodal connexion of the } \\
\text { second cylinder with the } \\
\text { first takes place far for- } \\
\text { ward in the node (often } \\
\text { in front of the area of in- } \\
\text { sertion of the trace), by } \\
\text { the gradual raising of the } \\
\text { roof of the second cylin- } \\
\text { der till it comes in con- } \\
\text { tact with lateral loops of } \\
\text { the trace or their continua- } \\
\text { tions forward (diagram). } \\
\text { The third cylinder joins } \\
\text { the second in front of the } \\
\text { node and closes the gap } \\
\text { formed in the roof of the } \\
\text { second. }\end{array}$ & $\begin{array}{l}\text { Adult type ; the ultimate ad- } \\
\text { axially directed limbs of the } \\
\text { lateral loops continued down- } \\
\text { wards and forwards as flanges } \\
\text { attached to the edges of the } \\
\text { gap in the second cylinder. }\end{array}$ \\
\hline
\end{tabular}


DIAGRAMS SHOWING THE DIFFERENT STAGES OF PROGRESSIVE COMPLICATION

- BY TRANSVERSE SECTIONS OF CORRESPONDING NODES, INTERNODES, AND LEAF-TRACES (continued). [The diagrams represent actual sections $\times$ I 5. ]

(2) Starved intermediate plants.

Internode.
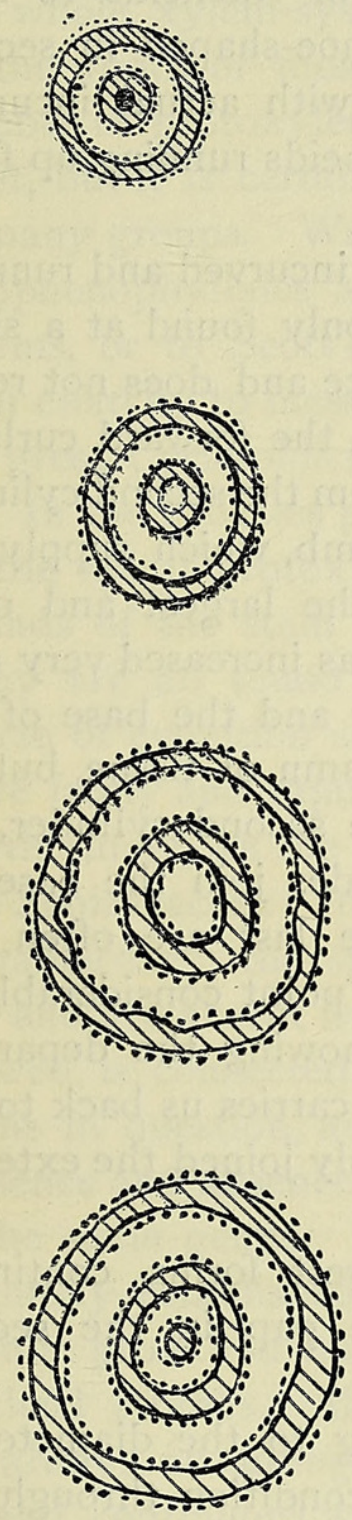

Node.
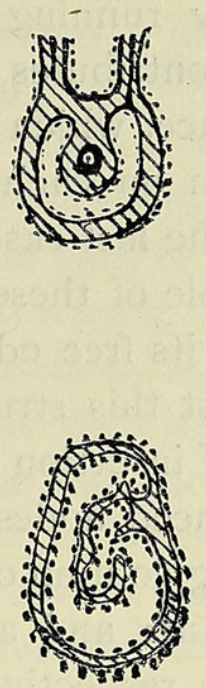

(3) 'Adult' plants.
Leaf-trace.

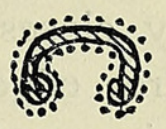

粮
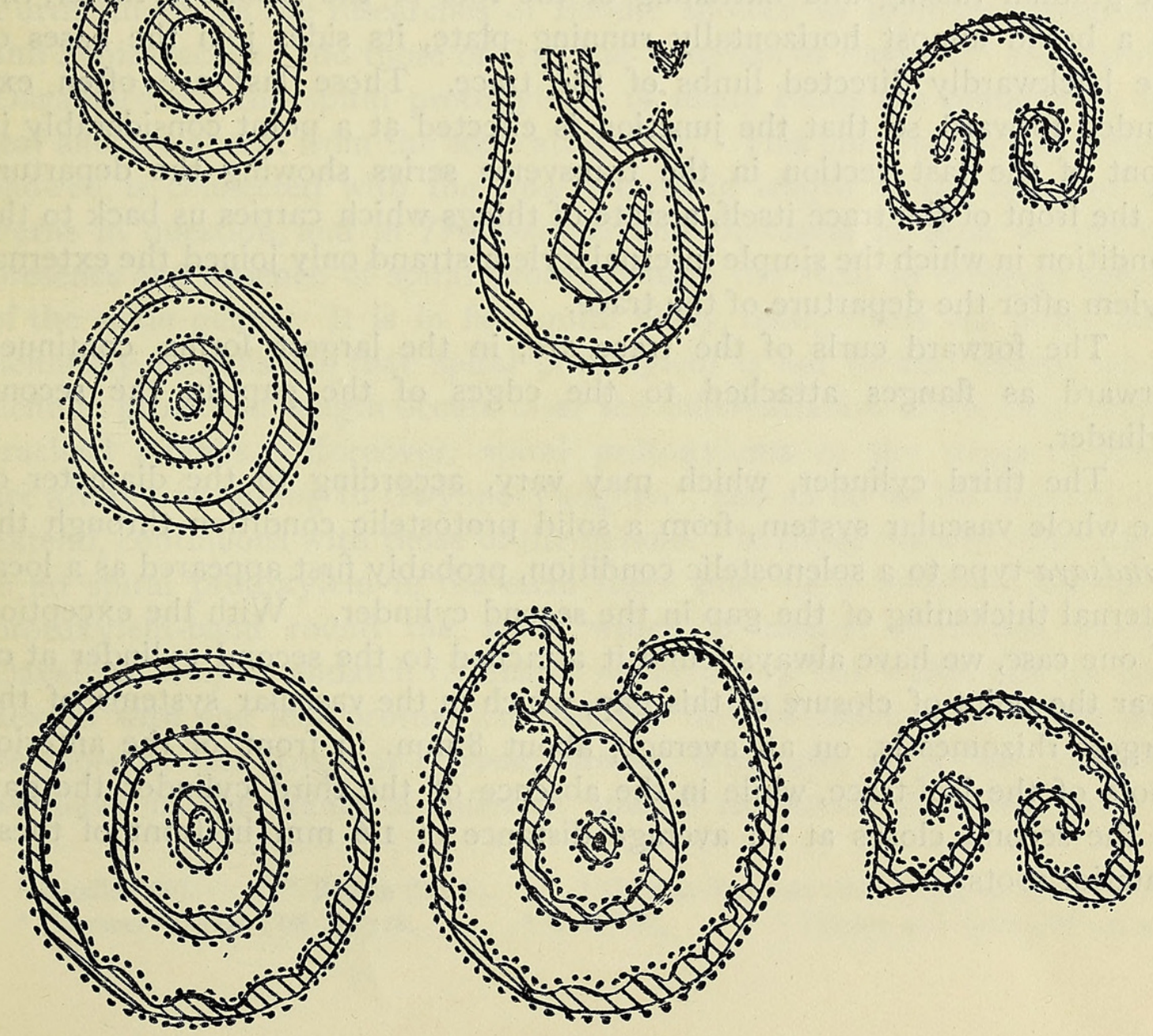

FIG. I3. Xylem diagonally lined, Phloem black, Endodermis dotted. 
a constant strand in the centre of the second cylinder. After a time an endodermal rod appears in the central phloem and dies out again; then a second, which likewise disappears, and so on. The stele is now much greater in diameter, and the space between its dorsal side and the internal cylinder considerably more. At the node the latter therefore sends up a distinct obliquely or vertically running column of tissue, which now invariably closes the gap and contributes a strand of tracheids to each of the free edges of the leaf-trace, which is horseshoe-shaped in section with an incurved hook of xylem on each side, or with actual incurved backwardly directed limbs. In the last case the tracheids running up from the inner cylinder supply the whole of these limbs.

The adult type of trace, with its free edges again incurved and running forward, is now reached. At first this structure is only found at a short distance above the actual point of insertion of the trace and does not reach down to its base. In more advanced nodes, however, the forward curls do reach to the base and the ascending column of tissue from the second cylinder branches on each side into an inner and an outer limb, which supply the backward and the forward curl respectively. In the largest and most advanced nodes the diameter of the second cylinder has increased very considerably and the connexion with the outer cylinder and the base of the leaf-trace is made, not by the sending up of a column of tissue, but by the gradual raising and flattening of the roof of the second cylinder, till, as a broad almost horizontally running plate, its sides join the bases of the backwardly directed limbs of the trace. These last are often extended forward, so that the junction is effected at a point considerably in front of the last section in the transverse series showing the departure of the front of the trace itself, a state of things which carries us back to the condition in which the simple internal xylem-strand only joined the external xylem after the departure of the trace.

The forward curls of the trace are, in the largest forms, continued forward as flanges attached to the edges of the gap in the second cylinder.

The third cylinder, which may vary, according to the diameter of the whole vascular system, from a solid protostelic condition through the Lindsaya-type to a solenostelic condition, probably first appeared as a local internal thickening of the gap in the second cylinder. With the exception of one case, we have always found it attached to the second cylinder at or near the point of closure of this gap, which in the vascular systems of the largest rhizomes is, on an average, about $8 \mathrm{~mm}$. in front of the anterior roots of the leaf-trace, while in the absence of the third cylinder the gap in the second closes at an average distance of $\mathrm{x} .6 \mathrm{~mm}$. in front of these anterior roots. 


\section{PROTOXYLEMS.}

The question of the morphological value of protoxylems is one of considerable interest. There is no doubt that in many cases at least the centres of differentiation of the xylem (Bertrand's pôles trachéens) are of morphological importance, affording a kind of basis, or skeleton, on which the whole xylem-system is built up. Not only is this clearly the case in the roots of most vascular plants, where the position and often the number of protoxylems within considerable circles of affinity is very constant, but it is certainly also the case in the vascular strands of the shoots of many groups. We need only refer to the universal exarchy of the steles of Sphenophyllales and Lycopodiales, and to the endarchy of the Angiosperms, or to Scott's important demonstration of the gradual transition from exarchy to mesarchy in the leaf-trace, and to endarchy in the stele, of the great Cycadofilicinean series, in order to emphasize the point.

In the Filicales proper the case is rather different. The exact position of the spiral protoxylems in relation to the metaxylem of the vascular strands of the stem is decidedly variable. Exarchy, endarchy, and mesarchy are all found within comparatively small groups, and the actual course of evolution seems to affect the position of the protoxylems much more freely and rapidly than in the other great groups of vascular plants. Furthermore, as the researches of Boodle showed in Hymenophyllaceae ${ }^{1}$ and Schizaeaceae ${ }^{2}$ and those of Gwynne-Vaughan in Loxsoma ${ }^{3}$ and various Davalliaceae ${ }^{4}$, the spiral protoxylems of many Ferns are confined to the leaf and are absent from the stem altogether. This phenomenon, as Boodle showed, is connected with the slow growth in length of the stems of the Ferns in question, and in Trichomanes and Dicksonia at least we get the presence and absence of spiral protoxylem in the stem in different species of the same genus. It is in fact quite likely, though this has never been definitely established, that spiral protoxylem is not formed except where definite growth in length occurs after the differentiation of the first formed tracheal strands. Moreover, spiral protoxylems in the stems of Ferns are always, according to Gwynne-Vaughan ${ }^{5}$, and so far as his observations extend, continuous with those of the petiole. In those cases in which there is no spiral protoxylem in the stem there may be a localized non-spiral protoxylem-band round the stele, which is exarch (Loxsoma, various Davallias, \&c.) or endarch (Schizaea malaccana ${ }^{6}$ ), but which has no connexion with the leaf protoxylem; or the differentiation of tracheids may be more or less irregular (Gymnogramme, Lindsaya, \&c.). In Dicksonia we have in the stems of different species the three cases-endarch or

\footnotetext{
${ }^{1}$ Boodle ('00). $\quad{ }^{2}$ Boodle ('01 A). $\quad{ }^{3}$ Gwynne-Vanghan ('01), p. 79, and ('03), p. 727.
}

- Gwynne-Vaughan ('03), p. $728 . \quad{ }^{5}$ 1. c. ('03). $\quad{ }^{6}$ Tansley and Chick ('03), p. 508. 
mesarch spiral protoxylem continuous with that of the leaf (D. rubiginosa, davallioides, adiantoides), exarch non-spiral protoxylem (D. apiifolia), and irregularity of xylem differentiation $\left(D\right.$. Barometz) ${ }^{\mathrm{T}}$. These facts, taken in conjunction with those obtaining in Trichomanes ${ }^{2}$, are sufficient to show that the existence of spiral protoxylem and even of localized protoxylem in any form is a highly variable phenomenon as between species and species in certain genera of Ferns, in striking contrast to its constancy in many other vascular plants. It is highly probable that a careful developmental study of the relations would generally reveal specific adaptation.

In Matonia pectinata, the distribution of the spiral protoxylems is of some interest, and so far as it goes certainly tends to show that the development of these structures is strictly dependent on the elongation of the stem after the beginning of tracheal differentiation.

In none of the six young plants $A$ to $F$, nor in the weaker starved plant (type G), can spiral protoxylem be detected in rhizome or petiole. We cannot state that no localized protoxylem of any kind occurs, because we have not succeeded in finding a good case of partly differentiated xylem in stele or leaf-trace. Apical growth appears to be very slow, and the complete differentiation of the vascular tissues extends to within a very short distance of the growing point. In the type of leaf-trace characteristic of stages IV to VI (see table, p. 498) the xylem usually consists of a central (abaxial) strand of narrow tracheids and two lateral wings of wider tracheids (P1. XXXII, Fig. 22). The central strand is in some cases very clearly distinct from the wings. It seems probable that this central strand may be formed before the wings, and thus represent protoxylem, but we have not succeeded in establishing spiral elements; in most cases the narrow tracheids are certainly scalariform. As the arch of the trace becomes broader (VII and VIII) the tracheids tend to become grouped in a series of curved bands as in the adult type, and small groups of narrow tracheids are distinguishable between the bands (Fig. 23), i.e. in the position of protoxylems in the adult; but these are not constant.

In stage IX $(\mathrm{H})$, however, a plant which, it will be remembered, had a much stouter rhizome and much longer petioles than any of the simpler ones, we meet with undoubted spiral protoxylems, both in the rhizome and petiole. The stelar system here consists of a solenostele, with an internal accessory solenostelic cylinder (Text-Fig. I4, A) supplying the lateral loops of the leaf-trace. The external cylinder has its xylem arranged in not very well defined arcs, like those of the adult (Seward ('99), Plate XVII, Figs. 8 and 9), with unmistakable spiral protoxylems (eight or nine in all) at their points of junction. On the ventral side these arcs are longer and broader than on the dorsal, so that the cylinder of xylem is thinner and has more protoxylems on the dorsal side, which

\footnotetext{
1 Gwynne-Vaughan ('03), p. 727.
}

2 Boodle ('00). 
is destined to form the arch of the leaf-trace. The internal cylinder has one distinct spiral protoxylem a little to one side of the mid-dorsal line. As the leaf-trace goes off five of the dorsal protoxylems enter the arch of the outer cylinder (by the time the trace is separated this number has been increased to seven by branching), while the single protoxylem of the inner cylinder takes up a median dorsal position, and runs up embedded in the tongue of xylem, which becomes separated

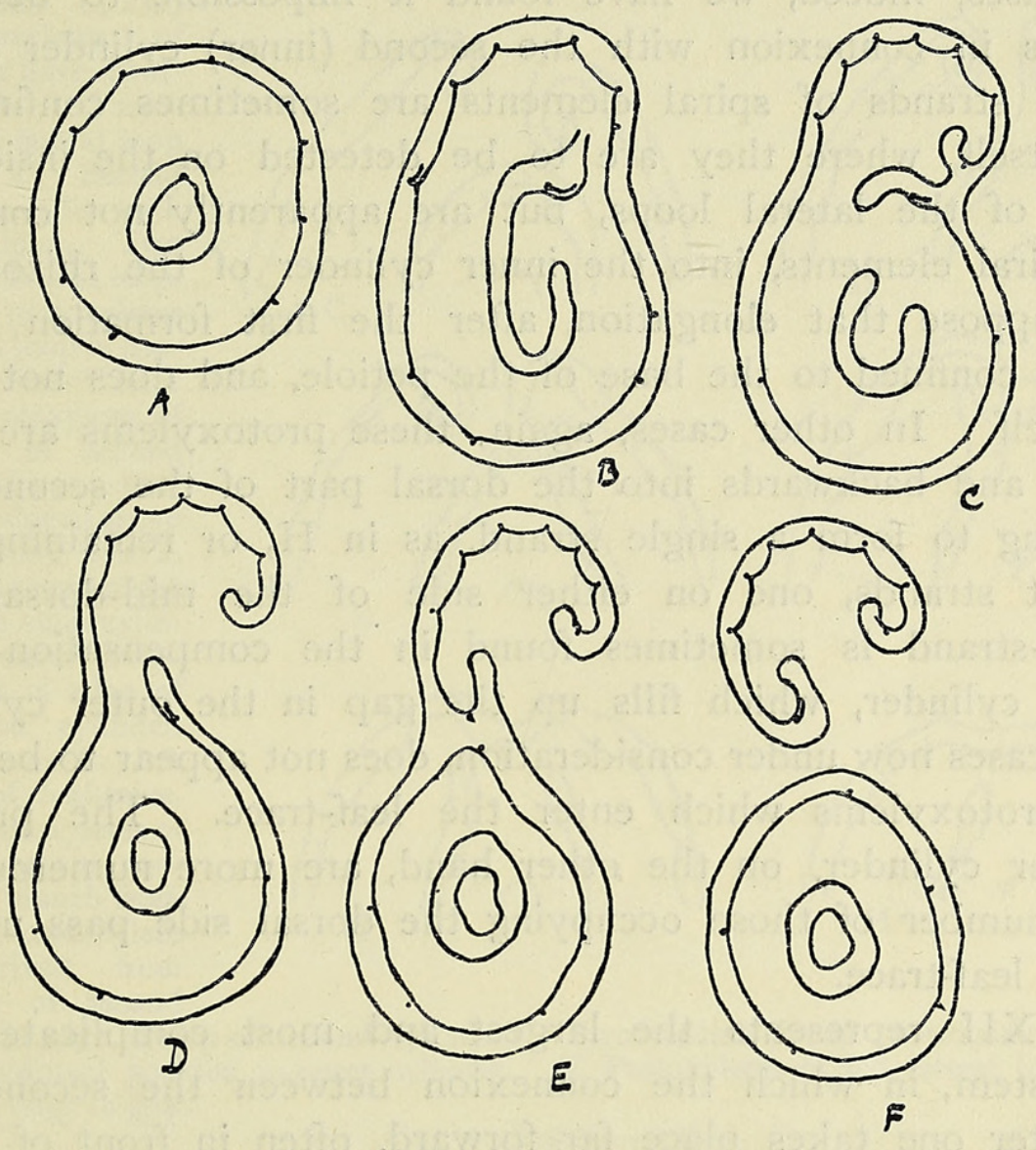

FIG. I 4. Diagrams of a series of transverse sections through the node of a dicyclic rhizome $(\mathrm{Plant} \mathrm{H})$, showing the course of the protoxylems. $A$. Internode; nine protoxylems in outer cylinder (five dorsal and four ventral) and one dorsal protoxylem in inner. $B$. Beginning of node; dorsal protoxylem of inner cylinder now in compensation-tongue sending off a branch to the right to run into right lateral loop of leaf-trace. C. Protoxylem of right lateral loop of leaf-trace separate. $D$. Dorsal protoxylem derived from second cylinder (now running in outer cylinder) branching to the left to run into left lateral loop. $E$. Protoxylem of left lateral loop separate. $F$. Leaf-trace detached from stele. Protoxylem of left lateral loop branching. Five protoxylems in outer cylinder, of which the dorsal one is derived, with the compensation-tongue, from the inner cylinder; the four ventral are as they were before the node was reached.

from the inner cylinder to form the lateral loops of the trace and close the gap in the outer cylinder. On the formation of the first lateral loop (the trace departs asymmetrically) the protoxylem branches, sending off a strand of spiral elements which enters the loop at its lowest point (Text-Fig. I4, B and C). After the detachment of the first loop the protoxylem sends a branch into the loop on the other side, itself continuing forward in the remainder of the tongue, which has now become 
part of the outer stele (Text-Fig. I4, D-F). The internal cylinder, which has thus lost its dorsal part and become gutter-shaped, is now without a protoxylem, but it soon closes up and another protoxylem appears in its dorsal region. The behaviour at the next two nodes is apparently similar.

In the smaller rhizomes showing the 'adult' type of leaf-trace (stages $\mathrm{X}$ and $\mathrm{XI}$ ) the protoxylems are often less developed than in stage IX. In some cases, indeed, we have found it impossible to detect spiral protoxylems in connexion with the second (inner) cylinder at all. In other cases strands of spiral elements are sometimes confined to the leaf-trace itself, where they are to be detected on the insides of the two limbs of the lateral loops, but are apparently not continued, at least as spiral elements, into the inner cylinder of the rhizome. Here we may suppose that elongation, after the first formation of xylemelements, is confined to the base of the petiole, and does not affect the rhizome itself. In other cases, again, these protoxylems are continued downwards and backwards into the dorsal part of the second cylinder, either joining to form a single strand, as in $\mathrm{H}$, or remaining apart as two distinct strands, one on either side of the mid-dorsal line. A protoxylem-strand is sometimes found in the compensation-tongue of the second cylinder, which fills up the gap in the outer cylinder, but this, in the cases now under consideration, does not appear to be connected with the protoxylems which enter the leaf-trace. The protoxylems of the outer cylinder, on the other hand, are more numerous than in $\mathrm{H}$, and a number of those occupying the dorsal side pass up into the arch of the leaf-trace.

Stage XII represents the largest and most complicated type of vascular system, in which the connexion between the second cylinder and the outer one takes place far forward, often in front of the actual departure of the trace. Here the protoxylem-system of the dorsal region of the second cylinder and of the gutters which continue forward the lateral loops of the trace is much more developed, in correlation with the much more considerable development and longitudinal extension of these structures, which form the apparatus of connexion between the trace and the second cylinder.

In the outer cylinder of this stage as many as eighteen protoxylems occur in a large rhizome. These are arranged closer together in the dorsal than in the ventral portion of the stele (Text-Fig. 15, A). A number of the dorsal protoxylems pass off with the main arch of the leaf-trace. The second cylinder may contain as many as nine protoxylems, though it often has only one or two, even in quite large forms. Of these there is always either one occupying the mid-dorsal line or a little to one side of it, or there are two, one on each side of the dorsal line. 
FIG. 15. Diagrams of a series of transverse sections through the node of a tricyclic rhizome. $A$. Internode shortly before node; dorsal protoxylems dividing up preparatory to formation of leaf-trace. Second cylinder with one dorsal protoxylem. Third with none. $B$. Second cylinder with three protoxylems. C. Two dorsal protoxylems of second cylinder have divided to form four. Protoxylem of right lateral loop branching. $D$. Second cylinder in connexion with right lateral loop. Two protoxylems in lateral loop. $E$. The two protoxylems of right lateral loop in connexion with a branch from right outer protoxylem of dorsal group of second cylinder. $F$. Two central protoxylems of dorsal group of second cylinder now in compensation-tongue, which has filled gap in outer cylinder. Right outer protoxylem remains in edge of gap of second cylinder. Two protoxylems in left lateral loop of leaf-trace. $G$. The two protoxylems or left lateral loop in connexion with a branch from left outer protoxylem originally derived from dorsal group of second cylinder (now in edge of gap of second cylinder). Two median dorsal protoxylems of this group seen in median dorsal position in outer cylinder. $H$. Protoxylerns of left lateral loop have joined protoxylem in edge of gap.
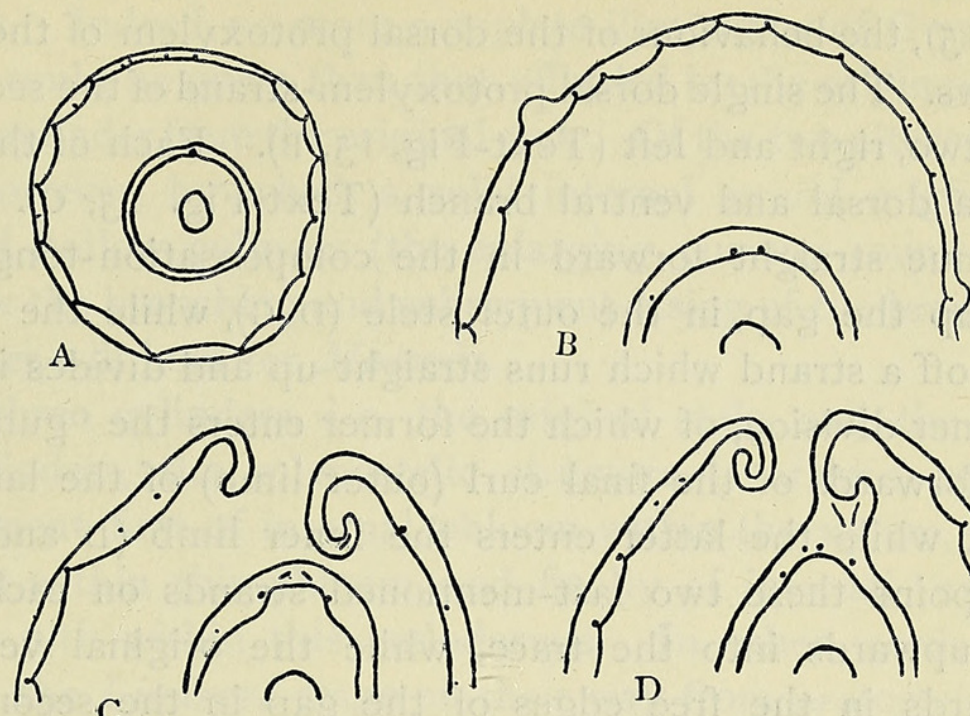

C

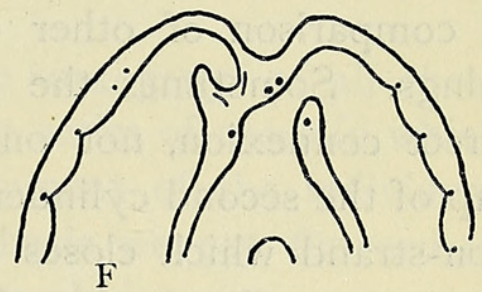

E
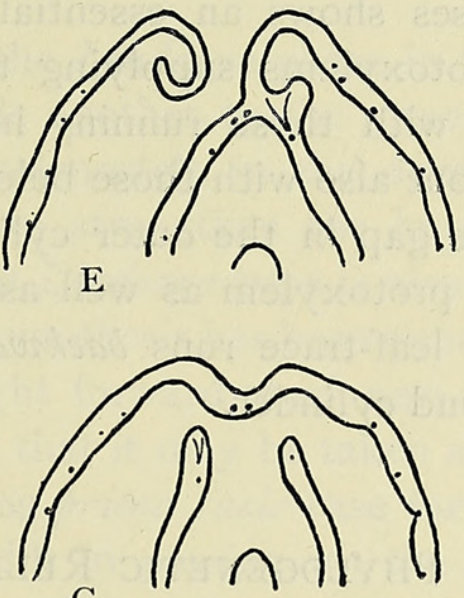

G

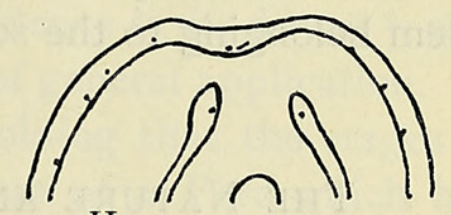

$\mathrm{H}$

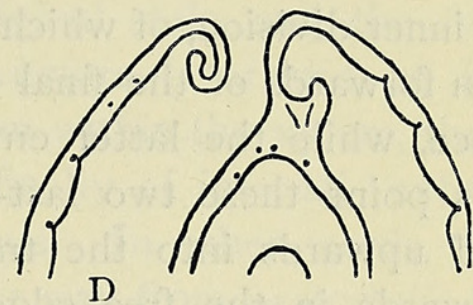
left lateral loop

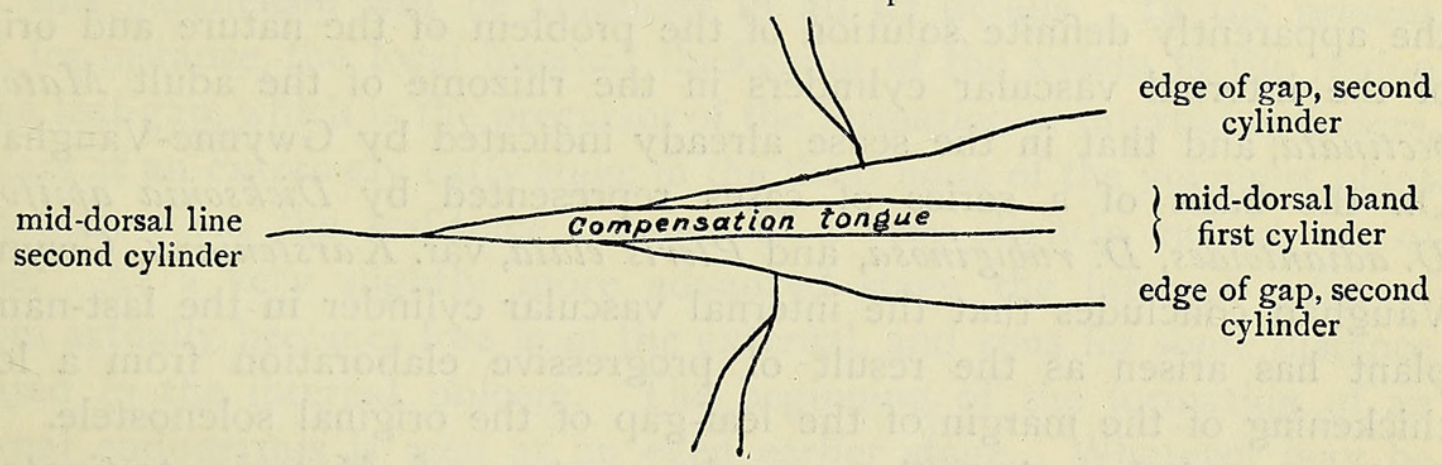

right lateral loop

J. Plan of protoxylems seen from dorsal side.

N.B. These figures are taken from a series through a very young node in which the protoxylems are the only parts of the vascular tissue differentiated. The main arch of the leaf-trace, which would be attached between $B$ and $C$, is not yet laid down, the forward extensions of the lateral loops (seen in $C$ to $F$ ) being the only part of the attachment of the trace to the stele as yet formed. The protoxylems of the left lateral loop (that nearest the apex of the stem and therefore the youngest) are not yet formed in $C$ to $E$, but only in $F$, where the loop is in immediate connexion with the upstanding flange on the edge of the gap of the second cylinder. 
In the case which we have been able to trace out most fully (TextFig. I 5), the behaviour of the dorsal protoxylem of the second cylinder is as follows. The single dorsal protoxylem-strand of the second cylinder branches into two, right and left (Text-Fig. I 5, B). Each of these then again divides into a dorsal and ventral branch (Text-Fig. I5, C). The dorsal branches continue straight forward in the compensation-tongue, which eventually fills up the gap in the outer stele (D-G), while the ventral branches each send off a strand which runs straight up and divides into two, an outer and an inner division, of which the former enters the 'gutter,' i. e. the continuation forwards of the final curl (outer limb) of the lateral loop of the leaftrace, while the latter enters the inner limb (D and E, F and G). From this point these two last-mentioned strands on each side run backwards and upwards into the trace, while the original ventral strands run on forwards in the free edges of the gap in the second cylinder (F, G, H). A comparison of other cases shows an essentially similar condition of things. Sometimes the protoxylems supplying the lateral loops are in direct connexion, not only with those running in the free edges of the gap of the second cylinder, but also with those belonging to the compensation-strand which closes the gap in the outer cylinder. In any case the important point is that the protoxylem as well as the metaxylem supply of the lateral loops of the leaf-trace runs backwards and upwards from xylem belonging to the second cylinder.

\section{The Nature and Phylogenetic Relations of the Vascular System in Matonia.}

\section{Morphological Position and Origin of the Matonia-type.}

The first general result obtainable from the foregoing observations is the apparently definite solution of the problem of the nature and origin of the internal vascular cylinders in the rhizome of the adult Matonia pectinata, and that in the sense already indicated by Gwynne-Vaughan ${ }^{1}$. On the basis of a series of cases represented by Dicksonia apiifolia, D. adiantoides, D. rubiginosa, and Pteris elata, var. Karsteniana, GwynneVaughan concludes that the internal vascular cylinder in the last-named plant has arisen as the result of progressive elaboration from a local thickening of the margin of the leaf-gap of the original solenostele. $\mathrm{He}$ further concludes that the vascular system of Matonia pectinata is 'essentially similar.' The detailed account we have given of the origin of the internal cylinders in the young plants of Matonia and in the weak

1 Gwynne-Vaughan ('03), pp. 703-5. The suggestions of Seward ('99, p. I 80) and Boodle ('01 B, p. 739) as to the splitting off of an internal ring from the original solenostele must be dismissed as untenable. 
rhizomes of relatively starved plants can leave no doubt whatever of the correctness of this view. Indeed, no more complete illustration of GwynneVaughan's hypothesis could be given than that afforded by the origin of the first internal accessory cylinder from the original stele. Of the two alternative suggested methods, however, by which a solid internal strand might be converted into a closed hollow cylinder (the enlarging, curving round and meeting of the edges, or the branching and subsequent fusing of the branches into a cylinder ${ }^{1}$ ), neither will hold for Matonia.

In the case of all three cylinders, i.e. the original stele, and the two internal accessory cylinders, the solenostelic structure is arrived at by means of the development first of internal phloem within the xylem, then of internal endodermis within this phloem, and finally of internal 'extrastelar' parenchyma or pith within this endodermis. In other words, the cylinders pass through the Lindsaya-stage on their way from protostelic to solenostelic structure.

The appearance of the Lindsaya-phase in the 'ontogeny' of all three cylinders of Matonia adds another to the growing series of cases in which this type precedes the solenostele in the development of the individual Fern-stem ${ }^{2}$, and serves to strengthen the hypothesis we put forward in a previous note ${ }^{3}$, that the Lindsaya-type is also the phylogenetic precursor of the solenostele. This hypothesis has been strongly supported by GwynneVaughan, who has brought forward much new evidence in its favour ${ }^{4}$, and we have now little doubt that it may be taken as of general application.

There is such a strong prima facie case for holding that the stages of vascular structure met with in passing up the stem of a Fern which has attained a certain degree of complication represent, in a general way, the phylogenetic stages through which the adult stem has passed in arriving at its present structure, that we need have no hesitation in interpreting the one in the light of the other, but we must remember that it does not follow that this parallelism will be complete in all its details. In the present case, for instance, the local internal thickening of the xylem in the region of the leaf-gap, which is the precursor of the formation of internal cylinders, appears at an extremely early stage in the third node of the youngest plant we found, when the leaf-trace consists of a very slightly curved arc of tissue. At a very slightly more advanced stage the internal ridge of xylem actually becomes free from the external, and runs for some distance isolated in the internal phloem. The beginning of the formation of an internal endodermis is seen at an even earlier stage. Whatever may be

1 Gwynne-Vaughan ('03), p. 704.

${ }^{2}$ According to Chandler (New Phytologist, vol. iii, p. I23), the Lindsaya-stage is general, preceding the solenostelic stage, in the bases of the young stems of many species of Ferns he has investigated, mostly dictyostelic forms. This is quite borne out by Chandler's full paper in the last issue of this journal (Ann. of Bot., xix, p. 365).

3 Tansley and Lulham ('02).

4 Gwynne-Vaughan ('03). 
the causes which led to the formation of an internal endodermis and internal accessory vascular cylinders, there can be no doubt that they did not arise at a correspondingly early stage in phylogeny to that in which they are seen in the young Matonia. We must suppose that in accordance with Darwin's well-known principle, this character has been inherited at an earlier and earlier stage of development, till it has appeared in the young plant at a very early period indeed.

Judged by the comparative method there is a distinct correlation between the type of leaf-trace and the type of stele with which it is associated. In general terms we may say that a compact circular, oval, or kidney-shaped trace is associated with the protostelic type (Gleichenia, Lygodium, Hymenophyllaceae), while the passage from the protostelic to the solenostelic type is marked by a broadening and opening out of the trace into the arch-shaped form (Lindsaya, Davallia repens, D. pinnata, $D$. aculeata). It is only after the definite establishment of this last type that we begin in some cases to get the development of accessory strands within the solenostele, and the further evolution of these is associated with a further elaboration of the leaf-trace (Dicksonia rubiginosa, Pteris elata, var. Karsteniana, Pteris aquilina, \&c.). It is obvious that in the ontogeny of Matonia pectinata the appearance of internal accessory strands is much in advance of corresponding elaboration in the leaf-trace.

\section{Functional Relations of the Vascular System of Matonia in connexion with its Evolution.}

In order to attempt to understand the factors which have led to the evolution of the Matonia-type of vascular system, we must endeavour to realize the conditions existing at each stage of the progressive complication described, which, we may now assume, took place along the lines indicated by Gwynne-Vaughan's Dicksonia-series, and confirmed by the history of development in Matonia itself.

Starting with a hypothetical solenostelic ancestor and the arch-shaped type of leaf-trace, we have to consider first of all the cause of the origin of the local thickening of the xylem of the leaf-gap, such for instance as Gwynne-Vaughan has described in Dicksonia apiifolia, \&c. This is clearly of the nature of a reinforcement of the water-conducting tissue at a point in the xylem-cylinder immediately beyond that at which the drain of water consequent on the diversion of the transpiration-current up the leaf-trace is first felt. It may be supposed that the additional tracheids provided serve as an addition to the water-channel supplying the tracheids of the stele beyond the node, which have their supply diminished by the relatively bulky leaf-trace. This development of an additional xylem in connexion with the leaf-gap assumes greater proportions in Dicksonia adiantoides, 
where the ridge is continued throughout the internodes, and the xylem is separated from the xylem of the stele except at the nodes, and greater still in $D$. rubiginosa, where, according to Gwynne-Vaughan, it takes the form of from one to three separate strands, which only come into connexion with the stele at the leaf-gap. Here we may suppose that three separate internal xylem-strands serve as a reservoir of water to supply the tracheids of the stele, when they are depleted, during active transpiration, by the diversion of the current passing along the stele. This view is supported by the fact that the xylem of the accessory internal strands is in connexion with the xylem of the stele only at the point where the supply of water, to compensate for that diverted to the leaf-trace, is required. This is simply the physiological expression of the view that these internal accessory strands correspond to some extent with compensation-strands (Ersatzstränge, faisceaux réparateurs) serving to 'compensate' the vascular system of the stem for the loss caused by the departure of the leaf-trace. This idea also finds support in the phenomena seen in the young plants of Matonia, as detailed on pp. 486-8, and summarized on p. 497 , in which the internal accessory strand either supplies tracheids to the xylem of the stele at the point from which the forward wing of the leaf-trace has departed, or sends up its whole dorsal half to fill the gap in the xylem made by the departure of the trace. It may be pointed out that the internal tracheal reservoirs have here no independent connexion with the roots, and therefore presumably no independent water-supply. We must suppose that they are filled from the xylem of the stele, when the water-supply is in excess of the needs of transpiration, and the pressure in the tracheal system consequently increased; depleted again when transpiration is active, and the pressure in the tracheids in the neighbourhood of the base of the leaf-trace consequently lessened. There seems no objection on physical grounds to such an assumption of reversible action, and no other way of giving a functional meaning to the internal accessory strands.

The tracheal system thus originating cannot, however, to speak metaphorically, long resist being drawn into supplying the leaf-trace itself. At least such a diversion obtains in the young Matonia, in Dipteris conjugata, where a small part of the conspicuous thickening of the leaf-gap edge forms the incurved hook of the leaf-trace ${ }^{1}$, and it has probably occurred extensively in many of the advanced polycyclic Ferns ${ }^{2}$, though it is not mentioned by Gwynne-Vaughan as existing in his Dicksonia-series. In Gleichenia pectinata, on the other hand, the thickening of the leaf-gap edge appears from Boodle's figures and descriptions ${ }^{3}$ to be mainly a decurrent extension

1 Seward and Dale ('01), PI. XLVII, Fig. 4.

2 e.g. Pteris aquilina; see Tansley and Lulham ('04). It is possible that in some cases the development of the internal accessory system may be exclusively related to elaboration of the leaf-trace.

${ }^{3}$ Boodle ('01), Pl. XXXIX, Figs. 26, 27. 
of the incurved edges of the trace ${ }^{1}$. In Matonia the case seems to be that as the leaf-trace increases in size, a number of tracheids from the internal strand run up into the wings of the leaf-trace, as these are departing from the stele. This diversion does not, however, interfere with what appears to be the original function of the internal strand, namely the compensation of the external xylem-cylinder, a compensation which from this time forward takes the form of an actual filling of the leaf-gap by the dorsal xylem of the internal strand (pp. 488-9). The free edges of the leaf-trace at this stage are distinctly thickened, and their further progressive elaboration into the complicated lateral loops characteristic of the adult type goes hand in hand with the progressive elaboration of the internal cylinder, the whole of both limbs of the lateral loop on each side being supplied from this cylinder, which itself becomes solenostelic and increases greatly in size, while its roof regularly closes the leaf-gap of the outer cylinder.

The second cylinder now finds itself in the position of the original stele at an earlier stage of development. Not only has the whole of its roof gone to supply the lateral loops of the trace, and to fill the gap in the outer cylinder, but the tracheids occupying the edges of the gap made by this departure are in actual continuity with those of the free edges of the trace, the water-supply here running backwards from the second cylinder to the trace. This channel is established at an early period of development, as is shown by the continuity of protoxylems between the flanges of the cylinder and the gutters of the trace (p. 508), and must aid considerably in the depletion of the second cylinder just in front of the node. It is this state of things, no doubt, which gives the condition for the development of the third cylinder as an appendage of the edge of the gap of the second, bearing exactly the same relation to it as the second originally bore to the first, and serving in the same way as a supplementary reservoir of water, drawn upon when transpiration is active. If this view be accepted, we need not suppose that those cases in which the third cylinder ends blindly in the pith represent cases of reduction and loss of function; they can be interpreted as earlier stages in the evolution of the third cylinder, which starts as an elaboration of the edge of the gap in the second and extends in both directions through the internodes till it becomes continuous throughout the rhizome. It has been shown (p. 495) that the complication of the third cylinder is nearly always greatest in the region of its junction with the second, where its evolution may be supposed to be furthest advanced, and is correlated with the diameter of the outer cylinder and consequently with that of the leaf-trace. The increase in the diameter of the leaf-trace gives space for the increase in size and importance of the lateral loops, and these in their turn increase the

1 In specimens of this plant obtained by Mr. Boodle since the publication of his paper, the thickening of the edges of the leaf-gap is entirely a downward extension of the leaf-trace edges. 
demand on the second cylinder, thus leading to the appearance and increase in complexity of the third.

It is legitimate to inquire why precisely should the complicated vascular system whose development we have described be developed in this particular species. Such a question is never easy to answer satisfactorily, but the following considerations may be put forward. It is necessary, in the first place, to assume a progressively increasing demand by the leaf on the conducting and storage capacity of the rhizome. If the frond of Matonia pectinata has originated from the compact Gleichenia-type existing in G. Alabcllata, G. quadripartita, \&c., as we have suggested (pp. 479-82), the greatly increased extent of lamina produced by the repeated addition of peripheral pinnae would certainly involve such an increased demand on the conducting-system, as compared with that of the hypothetical protostelic ancestor. Such an increased demand might be met by a corresponding increase in the breadth of the arch of the leaf-bundle and a correlated increase in the diameter of the stem-cylinder after it had become solenostelic. Up to a certain point no doubt it has been so met; but it is easy to see that an indefinite expansion of the leaf-bundle and rhizome-stele would involve a correspondingly indefinite increase in thickness of petiole and rhizome, and thus a constantly increasing thickness of relatively useless pith and a wasteful accumulation of material. An increase of the leafbundle by the development of its incurved free edges into the lateral loops, and a correlated development of accessory internal cylinders (by the elaboration of an original 'compensation thickening' on the edge of the leafgap) connected with the lateral loops would certainly economize space and material. The initiation of such a line of evolution may be attributed to the ease with which the original compensation-strand (second cylinder) can be drawn into supplying the free edges of the trace.

Roots. Nothing has hitherto been said about the connexions of the root-steles, which are presumably the sole means of the original supply of water, with the vascular system of the rhizome. The root-steles are attached to the outer cylinder exclusively, opposite the protoxylems. The roots are scattered along the whole length of the rhizome, without any particular relation to the nodes, except in the young plants, where there are nearly always two or three roots at the node (two often dorso-lateral with their steles attached close to the actual base of the leaf-trace), and often not more than two along the considerably greater length of internode. In the adult rhizomes the roots are in some cases, though by no means always, mainly attached to the ventral and ventro-lateral portions of the surface of the rhizome. The water-supply thus apparently enters the outer cylinder all along its course, though sometimes mainly from the ventral side. As we have pointed out above, it is clear that water can only enter the second cylinder through its nodal connexion with the outer one, and the third 
through its connexion with the second in front of the node. It seems impossible to avoid the belief that the accessory cylinders are filled through these connexions when absorption exceeds transpiration, and drawn upon again when transpiration exceeds absorption.

\section{IThe Morphological Status of 'Pith'; its Relation to Leaf-Gaps and Cortex.}

The questions relating to the morphological status of pith, the conception of 'ground-tissue' in morphology, and the like, which, in recent years, have been so much discussed by various anatomists, particularly by Jeffrey, Farmer, and Boodle, are brought prominently before the mind in considering the ontogeny and phylogeny of the vascular system of a form like Matonia, where the axis of the rhizome is occupied successively by tracheids, sieve-tubes, endodermis, and 'ground-tissue pith', in no less than three successive and complete cycles. Without attempting to discuss the whole of the questions that have been brought into the arena of this discussion, we cannot help expressing our belief that Jeffrey's theory of the intrusion of cortex into the stele is without foundation on developmental and comparative grounds, and has at best a merely metaphorical value; while Farmer's view ${ }^{\mathbf{1}}$, that the only valid distinction is that between vascular (in the wide sense) and non-vascular tissues, while perfectly good, and, so far as we are aware, never disputed since the time of Sachs and De Bary, as a fundamental physiological classification of the internal tissues of a vascular plant, yet radically ignores the morphological problems with which the anatomist is confronted when he is endeavouring to trace out the evolution of the tissues of vascular plants ${ }^{2}$.

In our view, the pith is morphologically an entirely new tissue, formed in the centre of the stele, in place of vascular tissue, which preceded it in ontogeny and phylogeny, but is always, in the Ferns, separated from the latter by endodermis. The fact that its histological characters are very similar to, or even identical with those of the cortex, gives us no information as to how the pith arose in the course of descent, which is the essence of the morphological question; while the general continuity of pith with cortex at the leaf-gaps, and the phenomena of 'endodermal' or 'ground-tissue pockets' considered as probable forerunners of a continuous ground-tissue pith, although they do furnish us with good evidence of stages in the phylogenetic origin of pith, at least in certain cases, do not take us one step towards a demonstration of the cortical origin of pith, but merely establish

1 Farmer and Hill ('02), p. 39'.

2 Farmer's view that tissues cannot be treated as morphological entities in the same way as members of the plant body (op. cit.) is interesting, but involves questions far too wide to be discussed here. It appears to strike at the root of the investigation of tissue morphology on evolutionary lines, a subject which has been pursued with so much success in this country during the past decade. 
a presumption that pith first arose in connexion with the cortex at the leafgaps. The only evidence which would establish the origin of pith by intrusion of the cortex would be proof that the cells of the cortex actually pushed into the stele during development from the growing point, or had done so at some time during the course of descent. The possibility of this has been admitted by Gwynne-Vaughan ${ }^{1}$, but all available evidence points to a formation of pith by meristematic cells which would otherwise have given rise to stelar elements. In default of evidence of actual intrusion, the fact that pith occupies a region of the axis previously occupied by a totally distinct kind of tissue leads, in our view, necessarily to the conclusion that it is a new tissue. The statement about the intrusion of cortex becomes not only metaphorical, but misleading; a true and useful statement, on the other hand, would be that the ground-tissue of the plant has now extended so as to occupy the axis of the stem as well as the periphery, by the development of a new tissue, the pith, whose histological characters and opposition to vascular tissue bring it within the wider concept of ground-tissue.

This view necessarily carries with it the consequence that pith is morphologically part of the stele, since it is the phylogenetic successor of vascular tissue. We find it impossible to understand how this conclusion can be escaped if morphology is to have an evolutionary meaning. The case of the young Matonia appears to show, further, that pith does not in all cases arise in connexion with cortex. In nodes $2,3,4,6,7,8,9$ of plant $\mathrm{E}$ there is no connexion between the pith of the stele and that of the cortex, though there is a connexion between the pith of the stele and that of the leaf-trace (when the latter is present), the trace being a closed cylinder with its pith shut off from the cortex, and sometimes consisting of a few cells only confined to the base of the trace. In nodes 6,7 , and 8 the leaf-trace possesses at its base an internal endodermis only which is connected with the internal endodermis of the stem cylinder. In the open type of trace, the pith of the stele is at first in connexion with the cortex only through that of the trace (e. g. E, nodes IO, II, I3, I4 ; F, nodes I to 7); while later on $(\mathrm{F}$, node $8, \& \mathrm{c}$.) the pith of the stele opens directly to the cortex of the stem at the base of the trace, as is the case in typical solenostelic ferns.

In Schizaea malaccana ${ }^{2}$ and in S. dichotoma ${ }^{3}$, where the leaf-trace has no pith, the non-continuous ground-tissue pith of the stem is normally in continuity with the cortex in the form of the endodermal or ground-tissue ' pockets.' Isolated strands of internal endodermis enclosing pith are sometimes met with, and these may, with Boodle ${ }^{4}$, be interpreted as the result of reduction from a type with continuous pith; though, for reasons given ${ }^{5}$, such an interpretation does not appear to be absolutely necessary.

\footnotetext{
1 Gwynne-Vaughan ('03), p. 737, \&c.

- Boodle ('03), pp. 519, 52 I.

2 Tansley and Chick ('03). $\quad{ }^{3}$ Boodle ('03).

5 Tansley and Chick ('03), pp. 500-2.
} 
In Anemia coriacea ${ }^{1}$ there is a continuous sclerenchymatous pith not in connexion with the endodermal pockets. This Boodle also interprets as a reduction-phenomenon, and the same applies to Platyzoma, where the pith has no connexion either with cortex or leaf-trace. But in the young Matonia there can be no reason to postulate reduction, and the evidence cited is, we think, sufficient to show that the pith of the stem does not necessarily arise in connexion with cortex ${ }^{2}$.

Boodle has made a suggestion with regard to the teleological cause of the origin of pith in Ferns. 'To admit of the insertion of a number of large arched bundles, the stele increased its diameter beyond the size required by the exigencies of water-conduction, and the central part of the xylem of the stele was transformed into parenchyma or other tissues 3.' This seems to us an extremely probable view, though we should be inclined to regard the Lindsaya-type as normally antecedent to the production of a parenchymatous pith ${ }^{4}$. But in certain cases at least the pith may well have had a specific function of its own from the outset. In species with superficial creeping rhizomes and large leaves on long erect petioles, the tissues of the rhizome on which the base of the petiole is inserted must be subject to a considerable strain, which might lead to rupture of the vascular system at the junction of leaf-trace and stele. This danger would certainly be lessened by the insertion of a T-piece of hard material, the stalk of which occupies the centre of the leaf-trace and the cross-piece that of the stele. This T-piece is represented by the strand of sclerenchyma in the concavity of the trace and the sclerenchymatous pith of the stele to which it is attached, as actually found in many Ferns. Additional solidity would be acquired by the connexion of the T-piece with the thick-walled cortex of the stem and base of the petiole, and this condition is actually realized in most cases, where the leaf-trace is open at the base, but it is not essential to the mechanical efficiency of the arrangement which appears to obtain in the young Matonia. In some cases the strand of sclerenchyma in the concavity of the trace is continuous with a sclerized pith in one (the basipetal) direction only (Davallia pinnata). A study of various living Ferns in their natural habitat is required to confirm or disprove this idea.

If the view taken above, that the pith is to be regarded as a new tissue of the stem, is just, it follows that the same considerations must hold of the internal accessory vascular cylinders of Matonia and equally of other poly-

1 Boodle ('01), p. $3^{87}$.

${ }^{2}$ Cf. also Gleichenia dichotoma. Gwynne-Vaughan ('03), p. 739, has set out the alternative methods of evolution of a pith in Ferns.

${ }^{3}$ Boodle ('03), p. 530.

- Partly because of the large number of cases now known (see p. 509, supra) in which the Lindsayatype precedes solenostely in ontogeny, and partly because, as Gwynne-Vaughan ('03) has shown, the type of leaf-trace associated with the Lindsaya-stele is still compact and would not require a wide medullated type of stele for its attachment. 
cyclic Ferns in which internal strands arise in the same manner. These accessory vascular strands are to be regarded as essentially new developments, which partially replace the pith, just as the pith at an earlier stage replaced the internal vascular tissues. They are parts of the stele, just as the pith is part of the stele, which has now become a complicated structure without losing its individuality ${ }^{1}$.

1 It is abundantly clear that the term stele must be restricted to the central cylinder of the axis, if it is to retain a morphological meaning, and that the concept of polystely, at least in the Ferns proper, must be definitely regarded as obsolete. We have expressly excluded the other cases of socalled polystely, Selaginella, Primula, Gunnera, Nymphaeaceae, \&c., a discussion of which would be out of place here. The idea put forward by Van Tieghem and Douliot, that several equivalent cylinders in a stem could arise by the successive forking of the original one found at its base, was upset by the work of Leclerc du Sablon and Jeffrey, who showed that the real origin of the so-called 'polystelic' condition was quite different. It is doubtful, indeed, if the concept of homology could in any case be applied to the different vascular strands called steles by Van Tieghem and Douliot, whatever their origin. From the nature of the case they certainly could not be morphologically equivalent in the evolutionary sense, which is the only accurately definable and consistent meaning we can attach to the word homology. But since the state of things on which the theory of polystely was based is, so far as we know, non-existent, there is no need to discuss it further. For the reasons given we have avoided applying the term stele to the internal cylinders of Matonia, considering them as accessory developments of the original ancestral stele, and as parts of the present complicated stele. 


\title{
BIBLIOGRAPHY.
}

Boonle ('00): On the anatomy of the Hymenophyllaceae. Ann. Bot., vol. xiv. ('01 A): On the anatomy of the Schizaeaceae. Ann. Bot., vol. xv.

('01 B) : On the anatomy of the Gleicheniaceae. Ann. Bot., vol. xv.

('03): Further observations on Schizaea. Ann. Bot., vol. xvii.

Bower ('99): The Leptosporangiate Ferns. Phil. Trans., B., vol. cxcii.

Chandler ('04): On the arrangement of the vascular strands in the 'seedlings' of certain Leptosporangiate Ferns. New Phytologist, vol. iii, p. I23.

Christ ('97): Die Farnkräuter der Erde.

FARMER and Hill ('02): On the arrangement and structure of the vascular strands in Angiopteris evecta, \&c. Ann. Bat., vol. xvi.

Gwynne-Vaughan ('01): Observations on the anatomy of Solenostelic Ferns. I. Loxsoma. Ann. Bot., vol. xv.

\section{('03): Ditto. II. Ann. Bot., vol. xvii.}

Jeffrey ('02): The structure and development of the stem in the Pteridophyta and Gymnosperms. Phil. Trans., B., vol. cxcv.

Ridley ('01): The flora of Mount Ophir. Journ. Roy. Asiatic Soc., Singapore branch.

Seward ('99): The structure and affinities of Matonia pectinata. Phil. Trans., B., vol. cxci.

Seward and Dale ('01): The structure and affinities of Dipteris. Phil. Trans., B., vol. cxci.

TANSLey and ChICK ('03): The structure of Schizaea malaccana. Ann. Bot., vol. xvii.

TANSley and Lulham ('02): On a new type of Fern-stele, \&c. Ann. Bot., vol, xvi.

('04): The vascular system of the rhizome and leaf-trace of Pteris aquilina,

\&c. New Phytol., vol. iii, p. I.

Wigglesworth ('02): Notes on the rhizome of Matonia pectinata. New Phytol., vol. i.

\section{DESCRIPTION OF FIGURES ON PLATES XXXI-XXXIII.}

\author{
Illustrating the paper by Mr. Tansley and Miss Lulham on Matonia pectinata.
}

\section{PLATE XXXI.}

Figs. I-7. Young plants of Matonia pectinata and detached leaves from the same. Natural size. (For details see text, pp. 477-9.)

Fig. 8. Very small dichotomously branched leaf from a starved plant. Nat. size.

Fig. 9. Simple leaf of adult type from a starved plant, showing 'middle pinna,' a single dichotomy on the left, and a tendency to dichotomy in the single pinna on the right. Nat. size.

Fig. Io. Frond of Gleichenia fabellata from the Kew Herbarium, showing the Matonia-type of frond-branching, with bud (adherent to one of the forks of the primary dichotomy) representing the 'middle lobe.' Reduced.

Fig. II. Transverse section of stele of proximal end of ririzome of youngest plant, A (Fig. I). end. endodermis; per. pericycle; tr. tracheids. Protostelic structure without phloem. $\times 400$ (p. 482).

Fig. I2. Transverse section of stele of rhizome of $\mathrm{A}$ immediately in front of first node. s. $t$. sieve-tubes; prot.c. proteid cells; ext.phl. external phloem. Lindsaya-phase. $\times 500(\mathrm{p} .483)$.

Fig. I3. Transverse section of stele of rhizome of $\mathbf{A}$ at origin of second leaf-trace. $x . t r$. xylem of trace; int.ph. tr. internal (adaxial) phloem of trace; int.ph. st. internal phloem of stele; ext. ph. st. external phloem of stele; per. rt. pericycle of root (cut tangentially). $\times 400$ (p. 483 ).

Fig. I4. Transverse section of third leaf trace of $\mathrm{A}$, while it is passing through the cortex, showing phloem massed mainly on adaxial side. Letters as before. $\times 400(\mathrm{p} .483)$. 


\section{PLATE XXXII.}

Fig. 15. Transverse section of proximal end of rhizome of plant D, showing central phloem enclosing a detached xylem strand and scattered endodermal cells uniting to form a crescentic strand. Sieve-tubes showing typical granules. $\times 160\left(\mathrm{p} .4^{8} 5\right)$.

Fig. I6. Transverse section of stele of proximal end of rhizome of plant $\mathrm{E}$, showing a solenostele with local internal dilatation of xylem. $\quad \times 130$ (p. 486).

Fig. I7. Transverse section through leaf-gap of fifth node of E. Internal xylem-strand free. $\times 100($ p. 486$)$.

Fig. 18. Next section but one; closure of gap; internal xylem-strand connected with outer xylem. $\times$ roo.

Fig. 19. Five sections further on ; tracheids running obliquely from central strand to close xylemgap. $\times \mathrm{I}_{50} \mathrm{O}\left(\mathrm{p} .4^{87}\right)$.

Fig. 20. Transverse section through fifth internode of $\mathrm{E}$, showing internal strand separated from outer cylinder dorsally by endodermis, ventrally also by pith; $p x$ ? probably protoxylem of leaftrace continued down into stele. $\times 120($ p. 487$)$.

Fig. 21. Transverse section of the beginning of the tenth node of $E$, showing tracheids from the internal strand running up into the leaf-trace, and phloem-elements in the interior of the internal strand. $\times$ I 30 (p. 487 ).

Fig. 22. Transverse section of the eleventh leaf-trace of $\mathrm{E}$, near its base; sieve-tubes mainly round the convexity of the trace; $p h . f$. ? probably fibres developed in phloem of concavity of leaftrace; $p x$ ? probably protoxylem; int. end. internal endodermis. $\times 500$ (pp. 488, 504).

Fig. 23. Transverse section of a leaf-trace of $G$, near its base, showing the initiation of lateral loops by thickening of the free edge of the trace (left) and xylem-hook formation (right). $p x$ ? probably protoxylems. In the phloem covering the sides of the trace the sieve-tubes are normal; round the middle of the convexity, thick-walled; in the concavity of the trace and in the loop of the xylem-hook on the right, fibres are developed instead of sieve-tubes. $\times 35^{\circ}$ (pp. 49I, 504).

Fig. 24. Diagram of transverse section of tricyclic stem in front of node, just before closure of gap in second cylinder. $\times 8$.

Fig. 25. Connexion of third cylinder with edge of gap in second, effecting closure. $\quad \times 8$.

Fig. 26. Gap closed; detachment of third cylinder from second. $\times 8$.

\section{PLATE XXXIII.}

Drawings of wax models of the stelar system.

Fig. 27. Side view of eighth node of F. $\times 25$.

Fig. 28. Front view of eighth and ninth nodes of F, showing connexion of second cylinder with outer one in front of insertion of ninth trace. $\times 40$.

Fig. 29. Segment of vascular system of rhizome and base of leaf-trace including front part of node, in simple dicyclic type, showing branching column of tissue rising from second cylinder to supply the lateral loops of the trace and close the gap in the first cylinder. Seen from behind. $X$ I 2 .

Fig. 30. Segment of vascular system of rhizome and base of leaf-trace including front part of node in most advanced tricyclic adult type, from behind. $a$. Roof of second cylinder rising to fill gap in first and coming into connexion with lateral loops of leaf-trace which bulge back freely above connexion; $b$. these backward bulges ; $c$. free edge of forwardly directed limb of lateral loop; $d$. downward and forward continuation of $c$, forming flange on edge of gap in second cylinder. $\times$ Io.

Fig. 3 I. The same from in front; same lettering. $\times 10$. 
Annats of Botany.
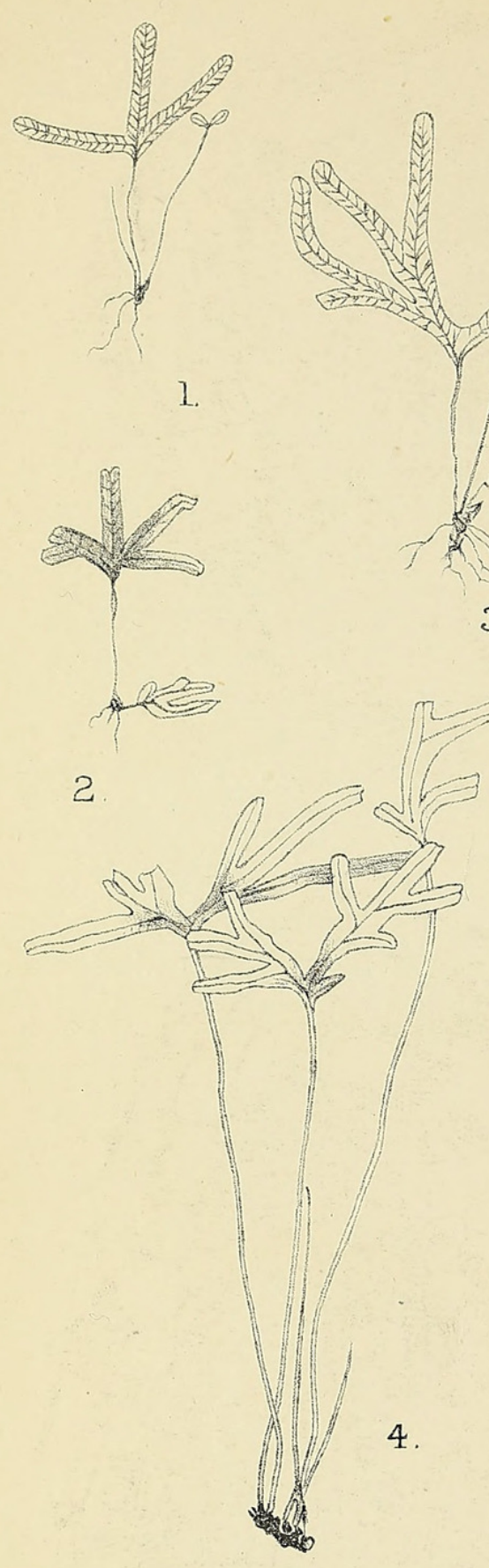

3
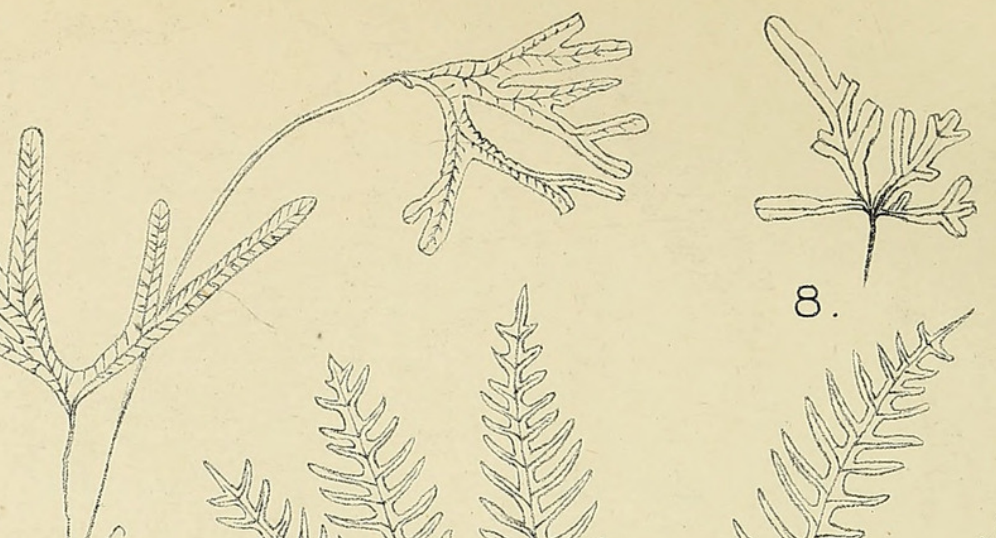

8.

end
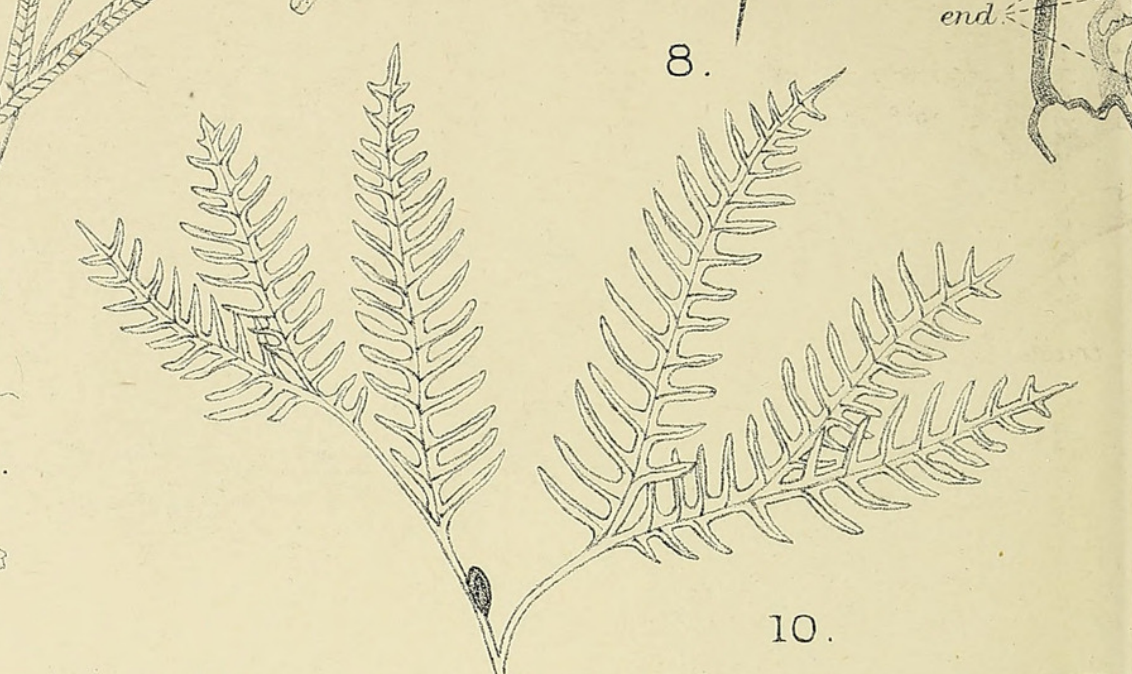

10.
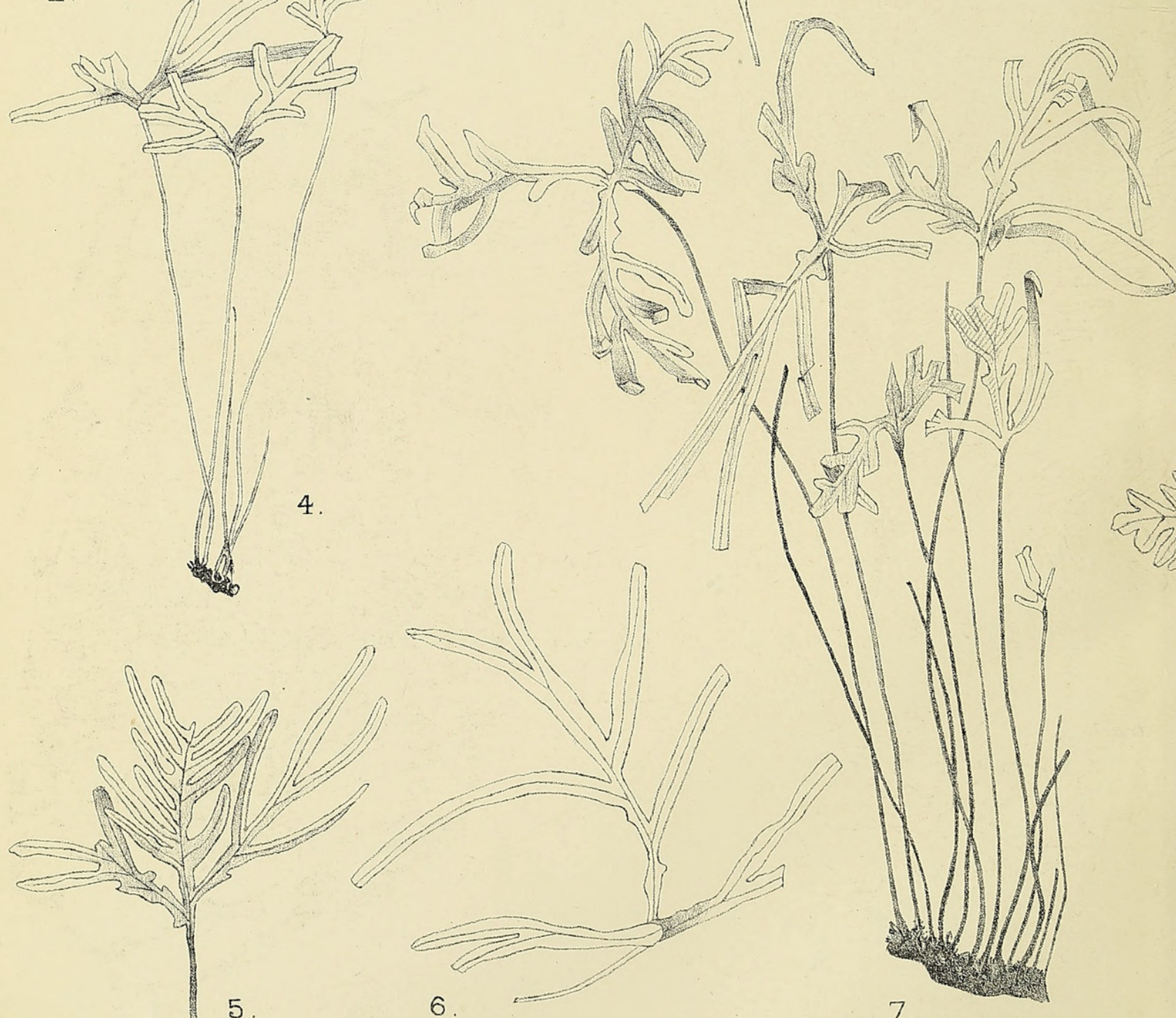

7

TANSLEY \& LULHAM. - MATONIA PECTINATA. 

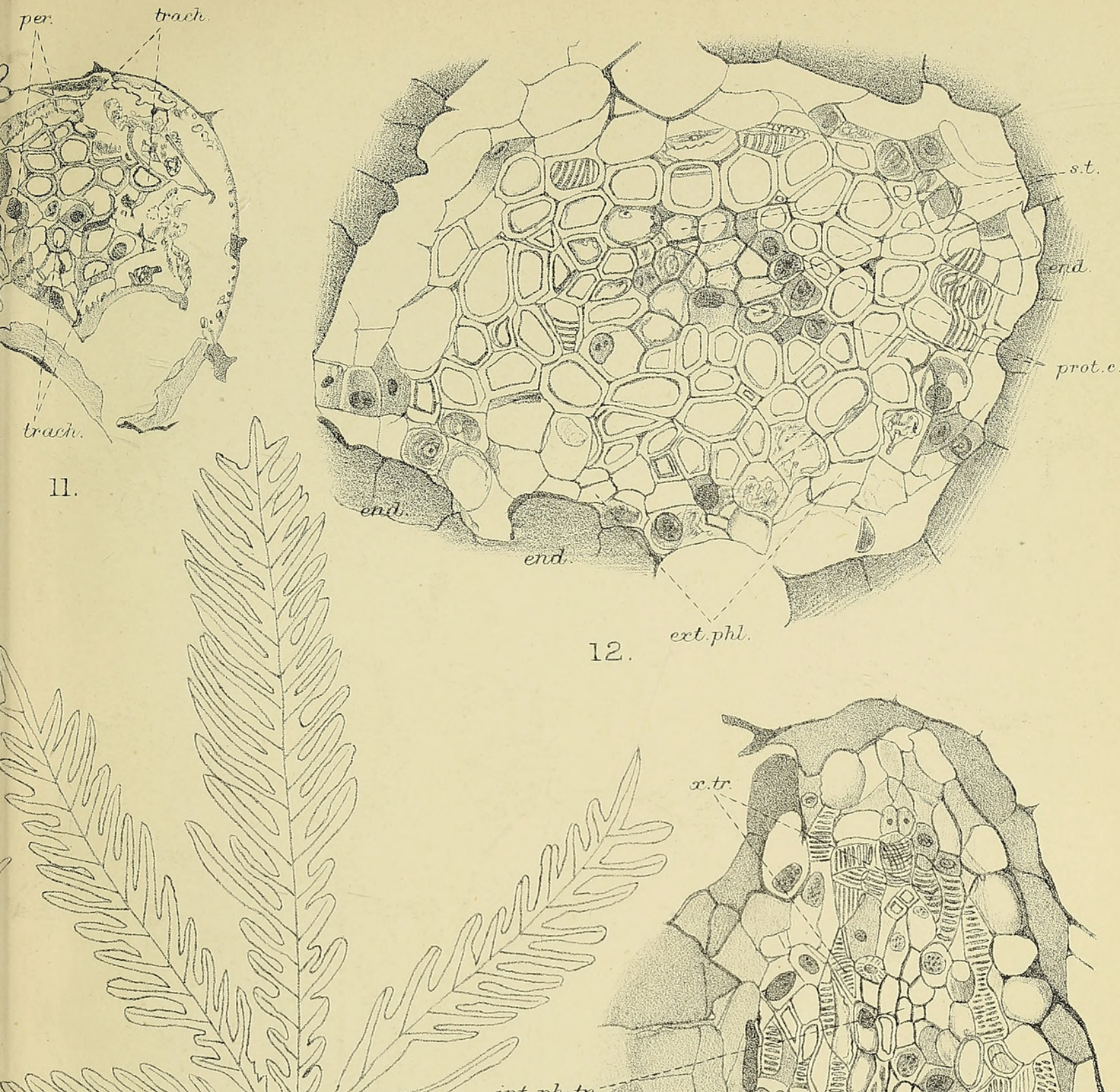

11.

12
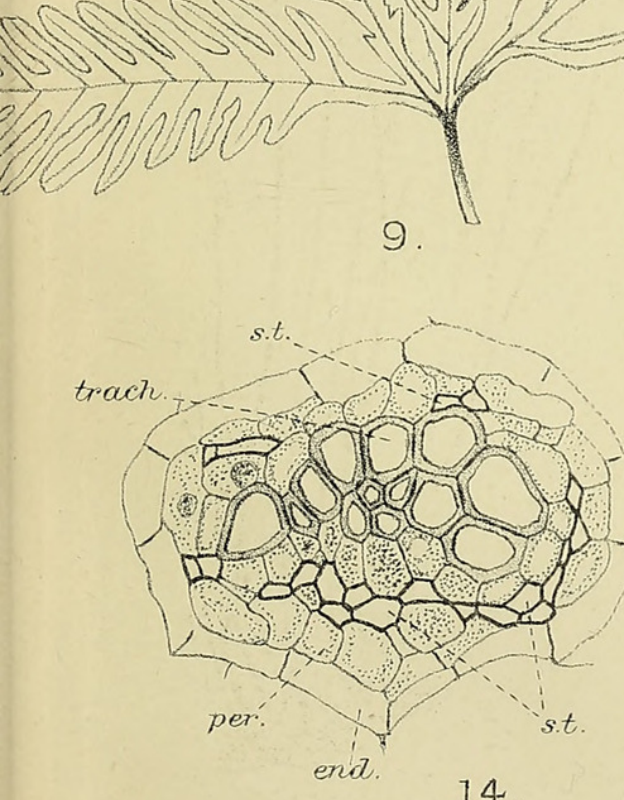

14. 

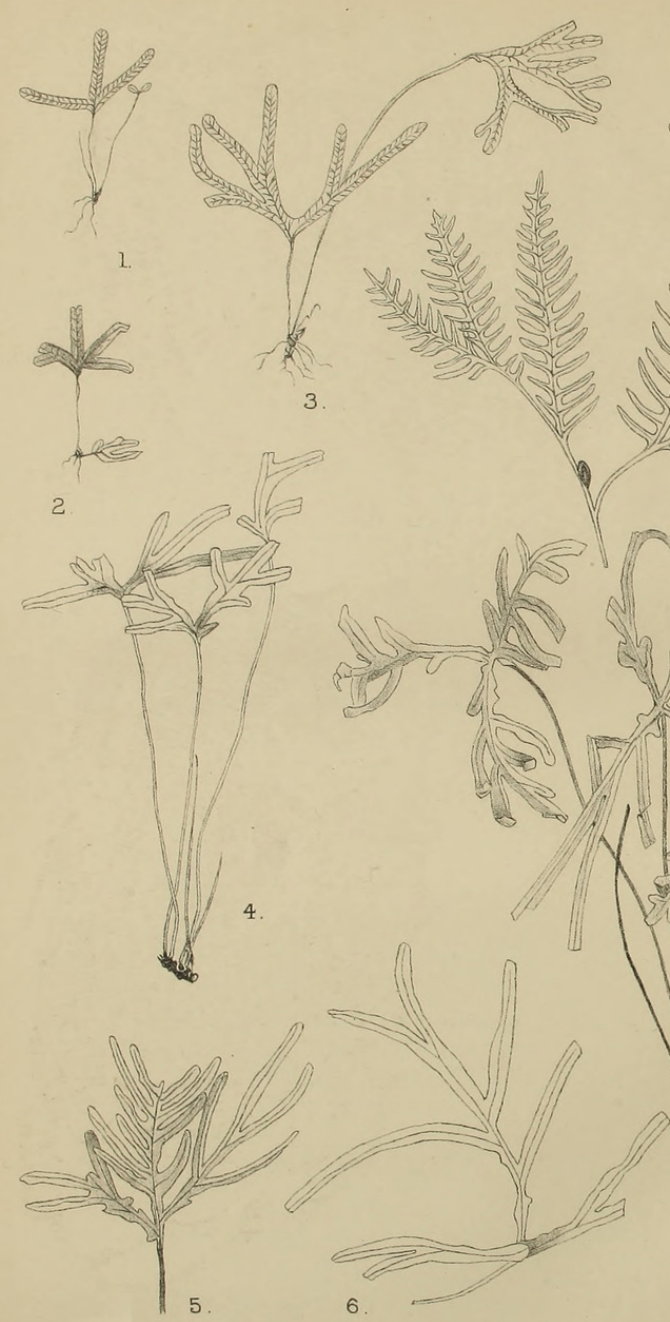

TANSLEY \& LULHAM - MATONIA PECTINATA
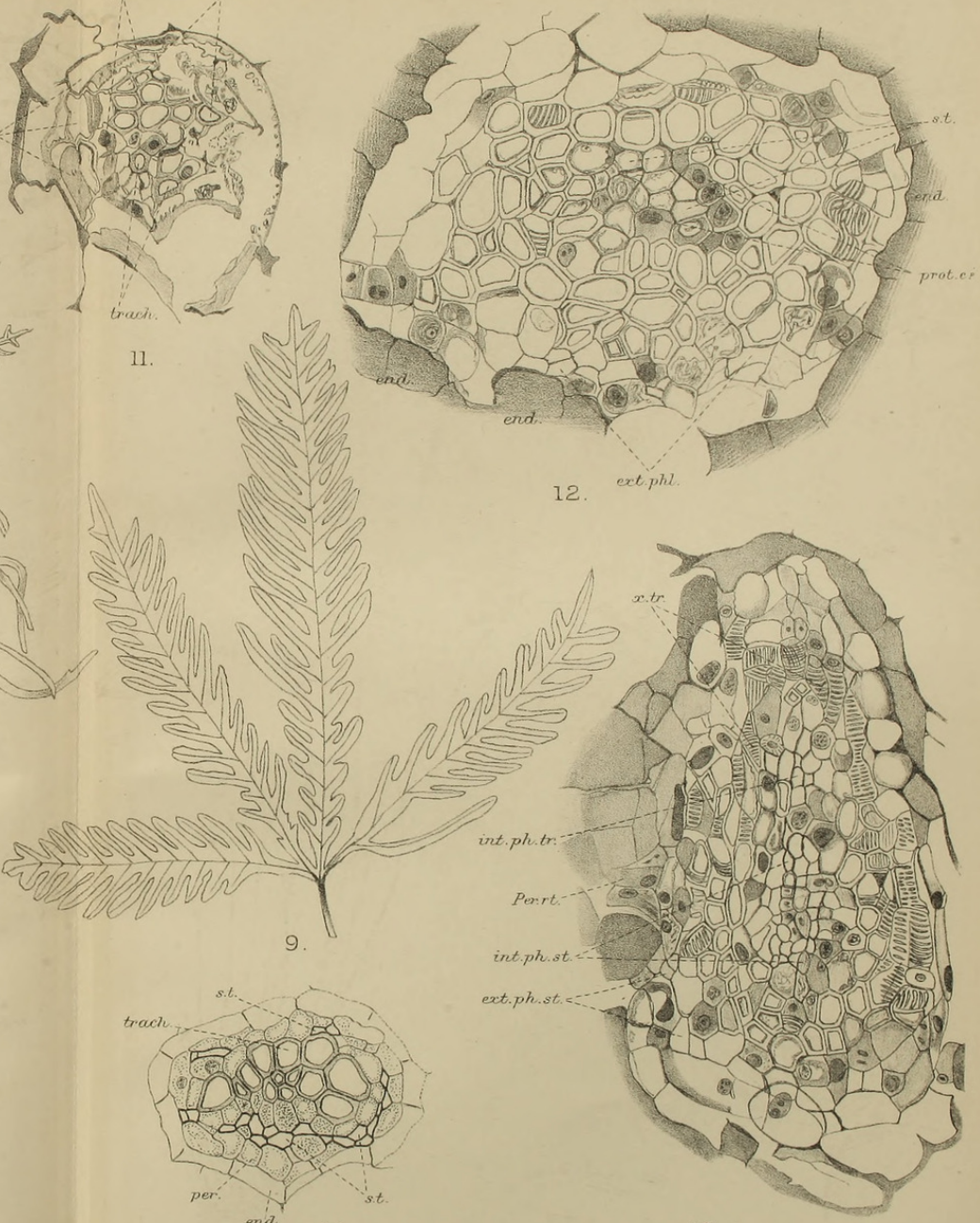

13.

Huth lith. et imp. 


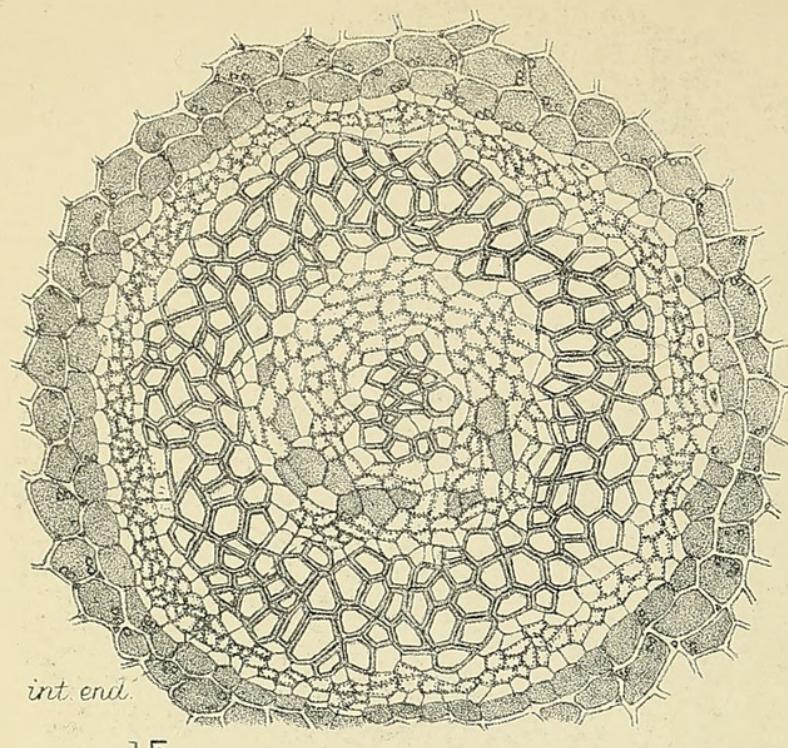

15

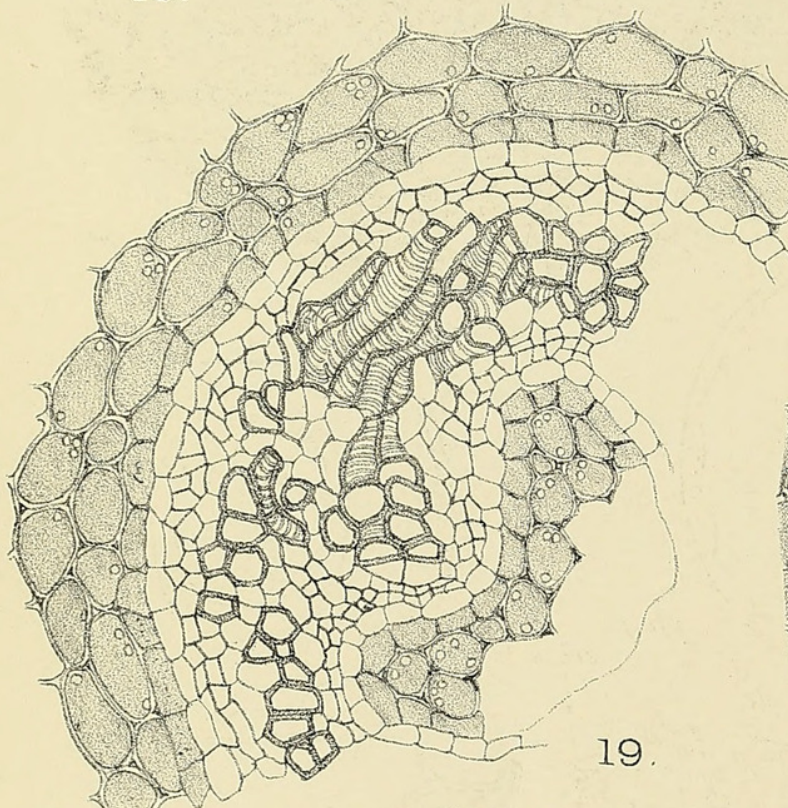

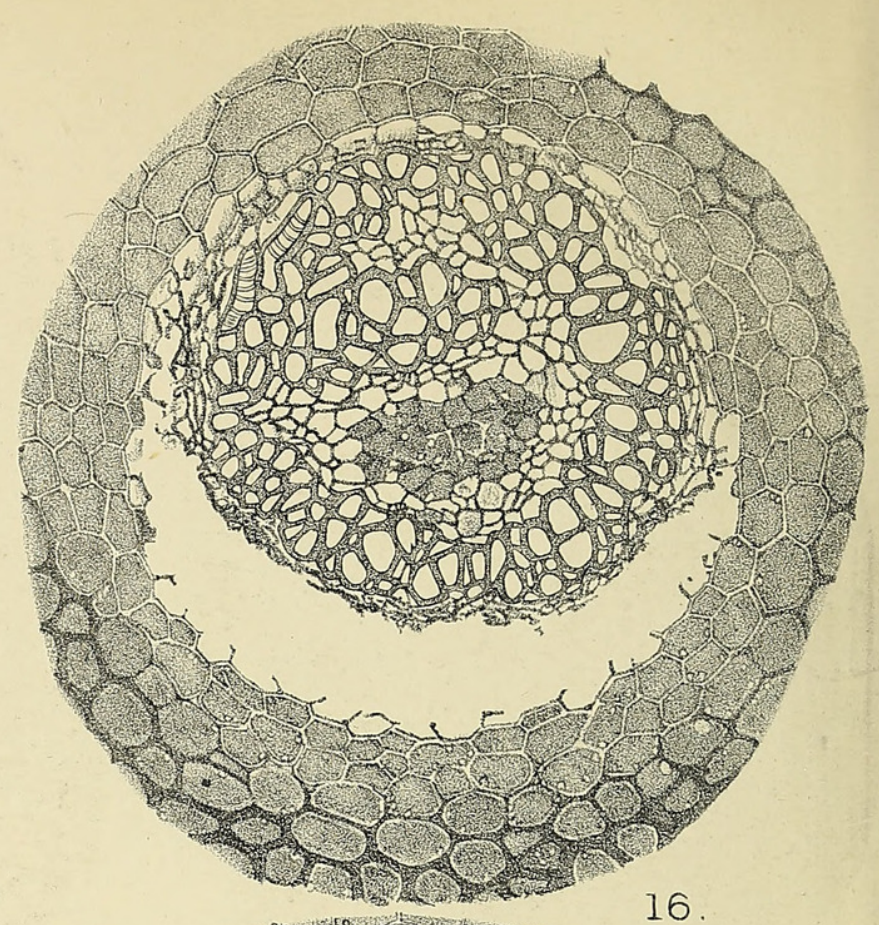

16
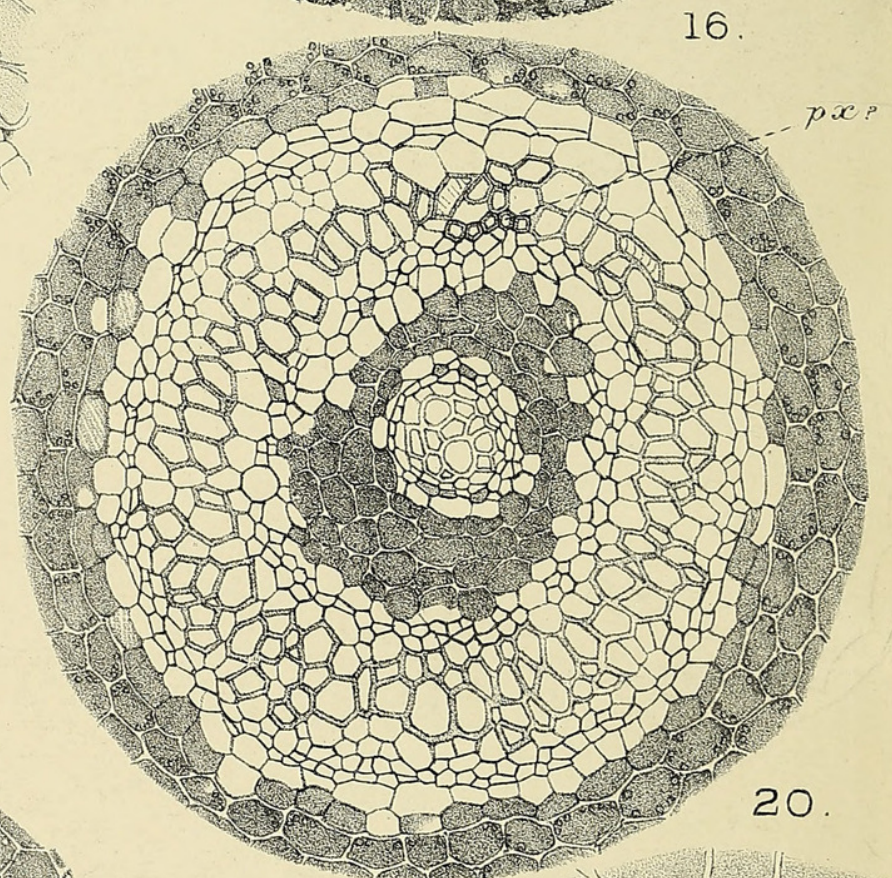

1.2.

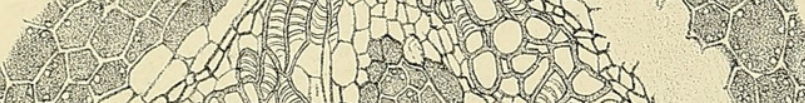

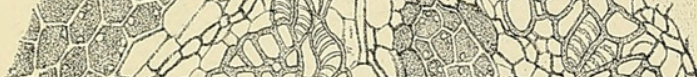

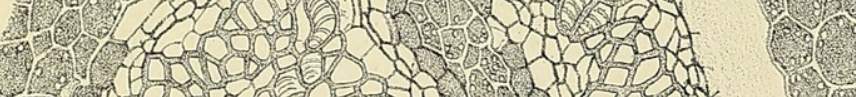

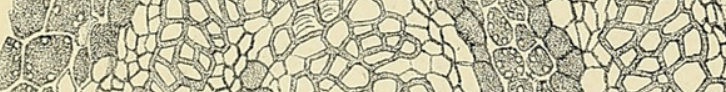

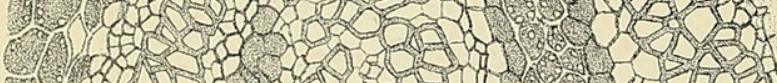
- 3920 y

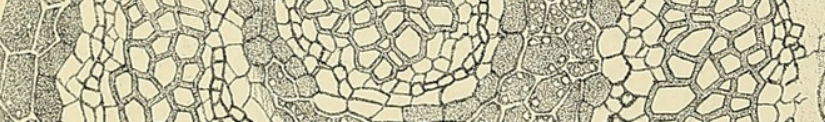

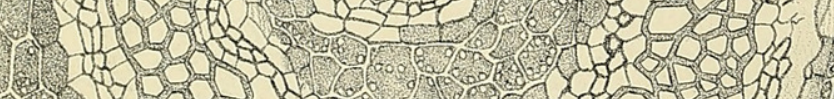

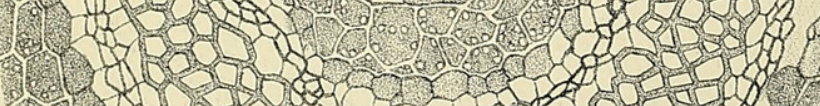
- 2010 m 3.

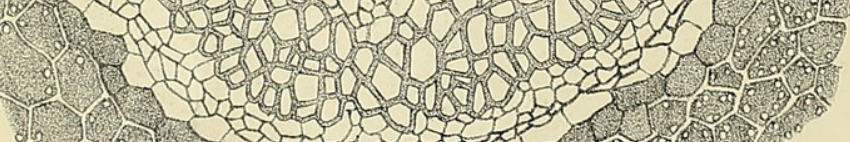
- 160 .

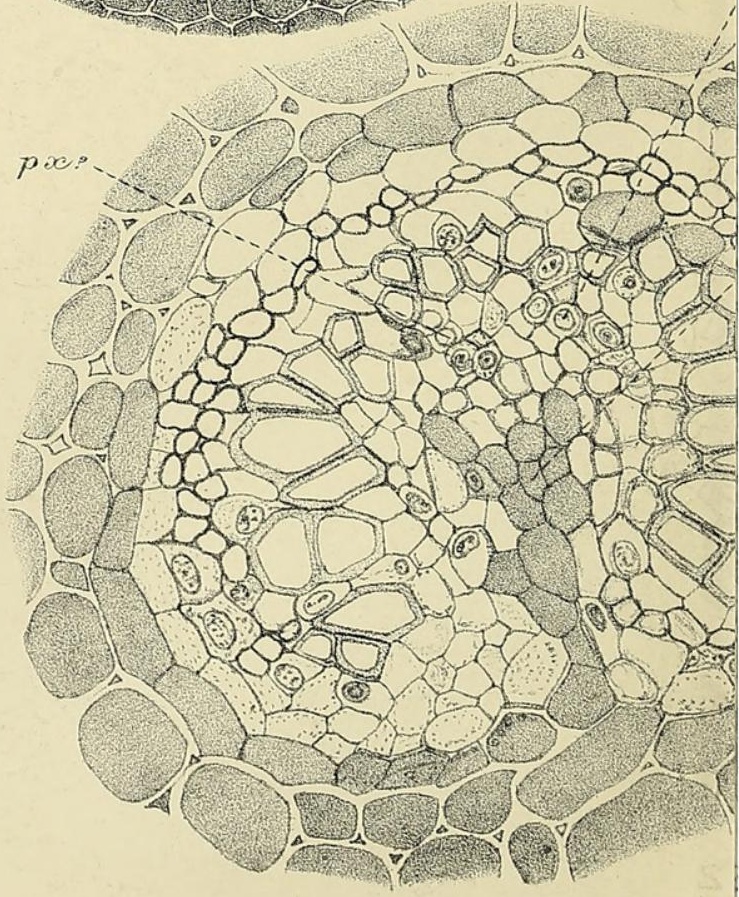



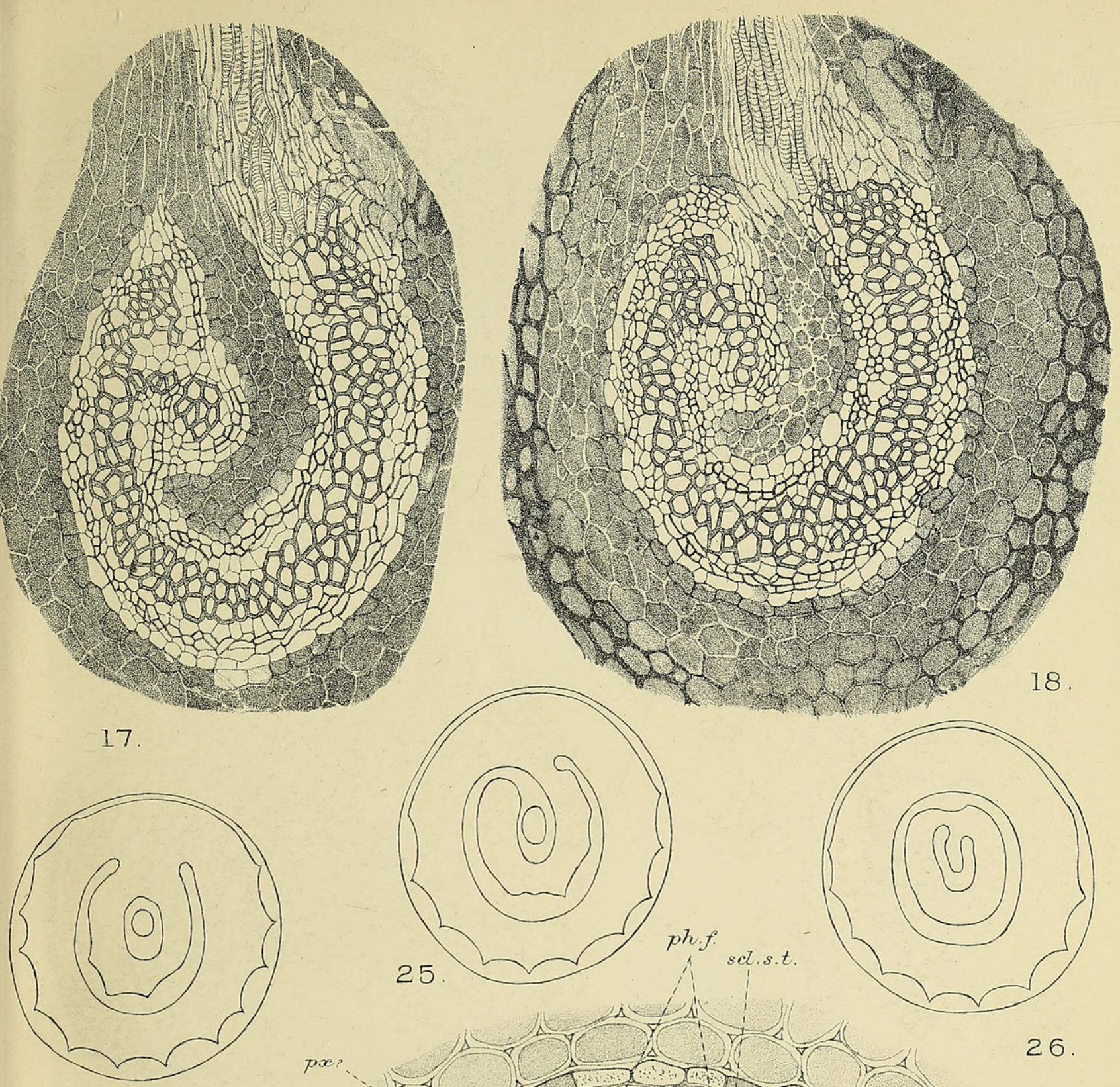

26

24

intend

$-1$

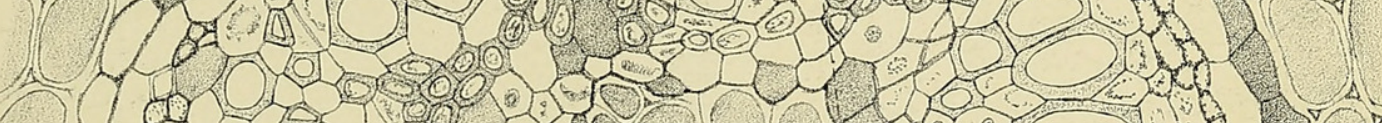

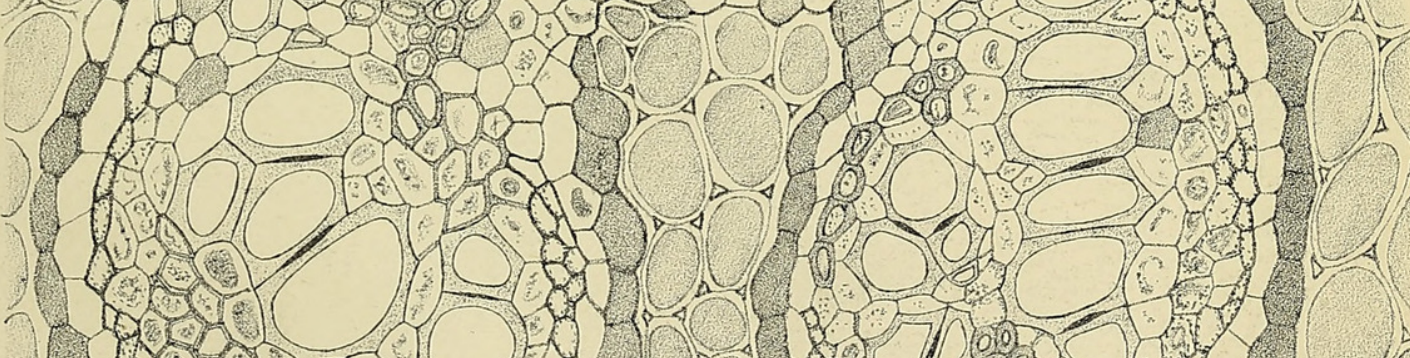
(a) s. 72 


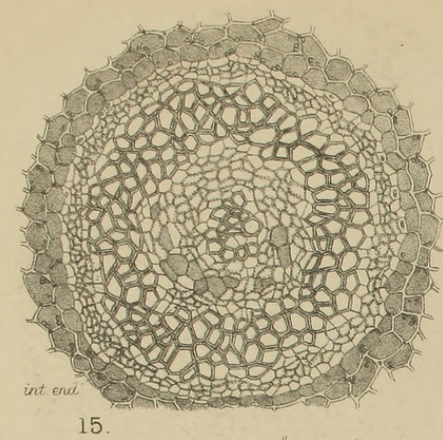

15
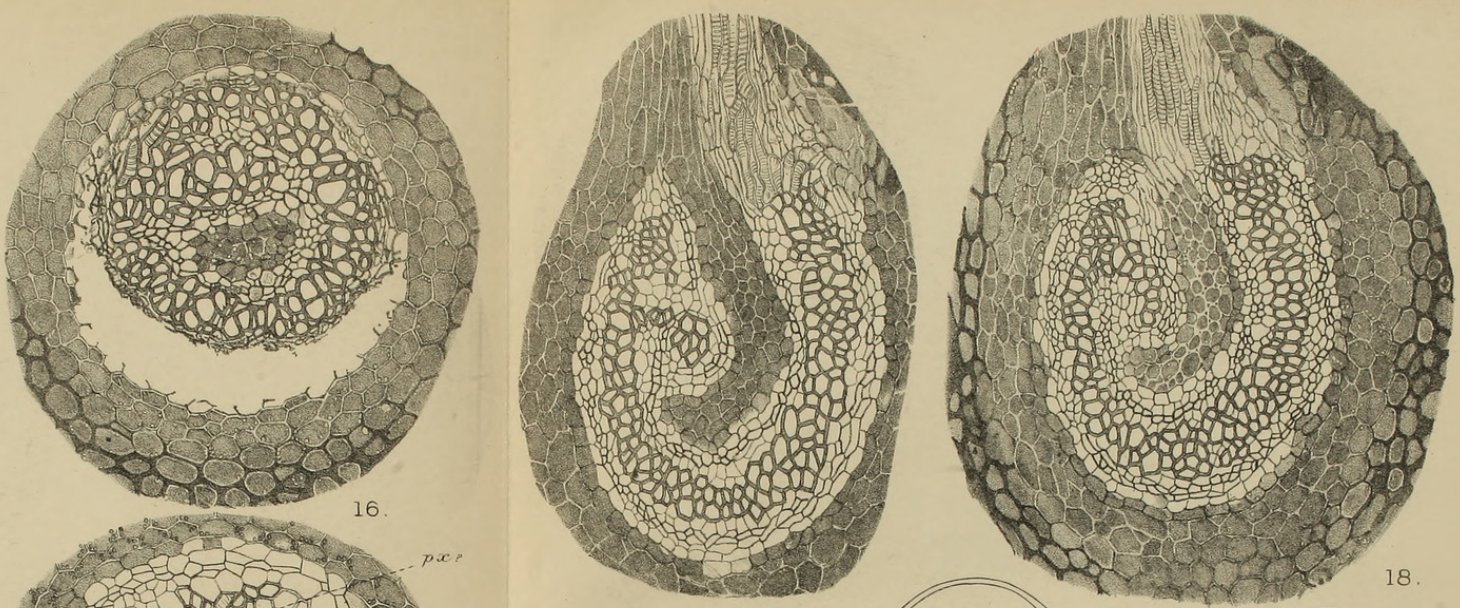

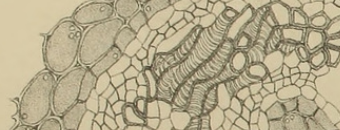

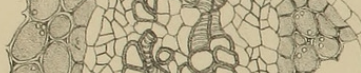

- 105000 t?

1.

1. M

19
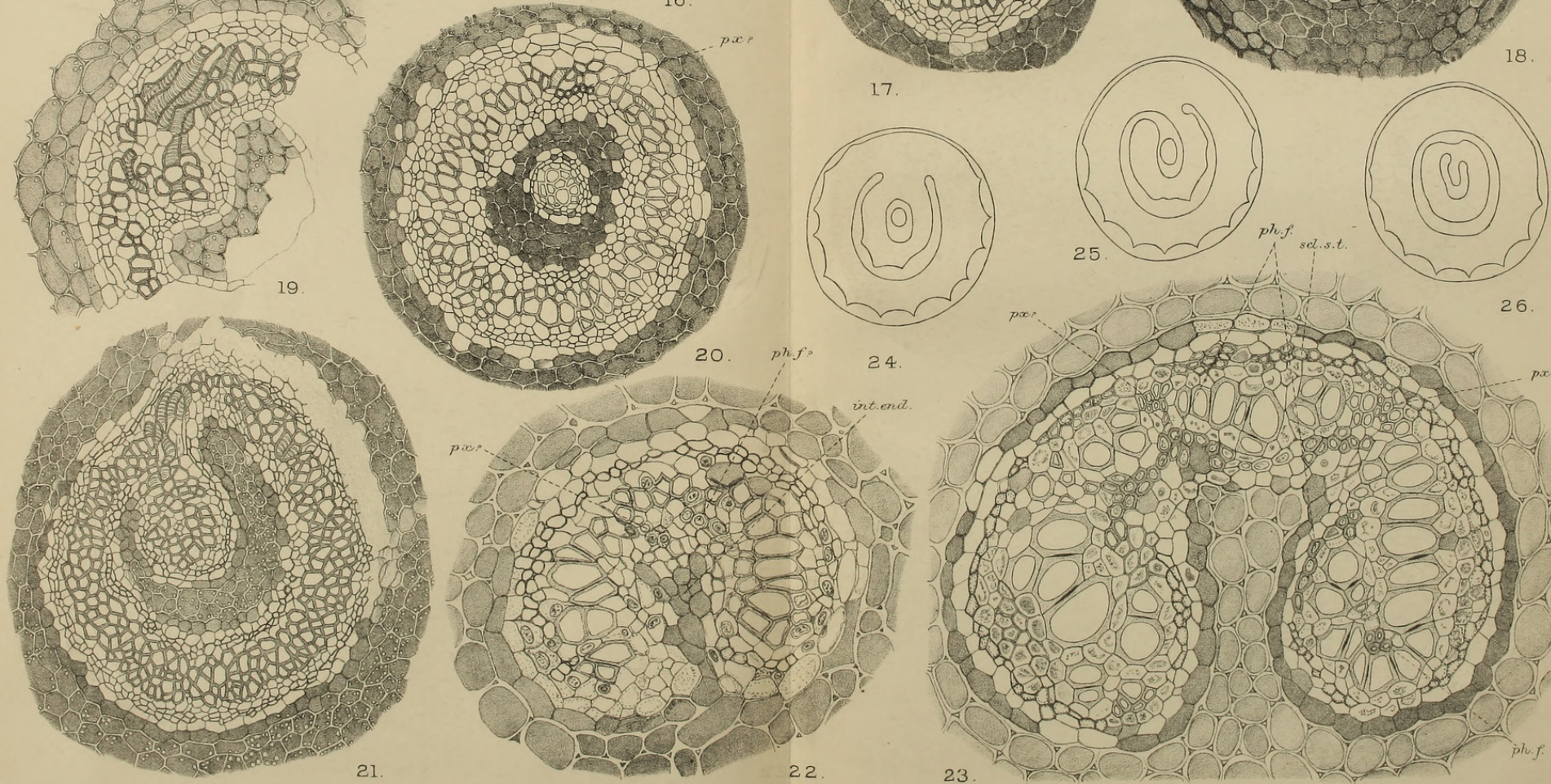

24

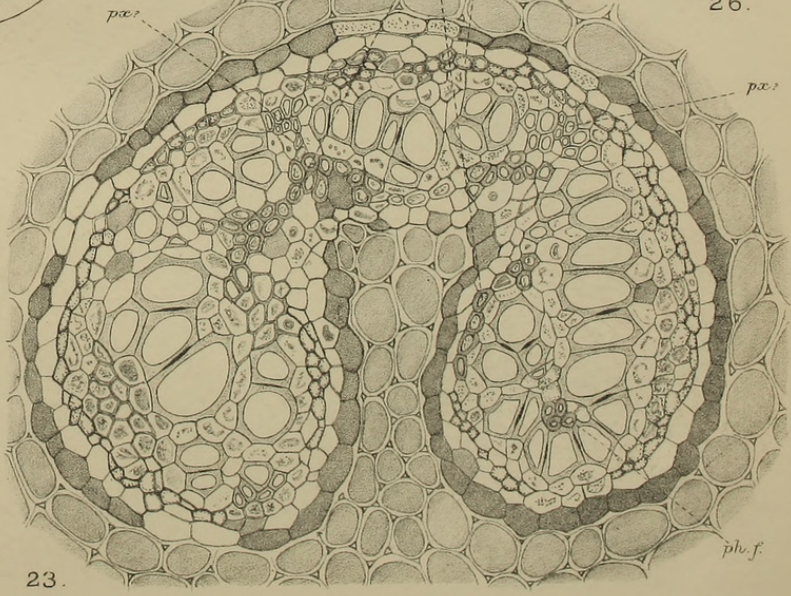

TANSLEY \& LULHAM - MATONIA PECTINATA 
Annals of Botany.
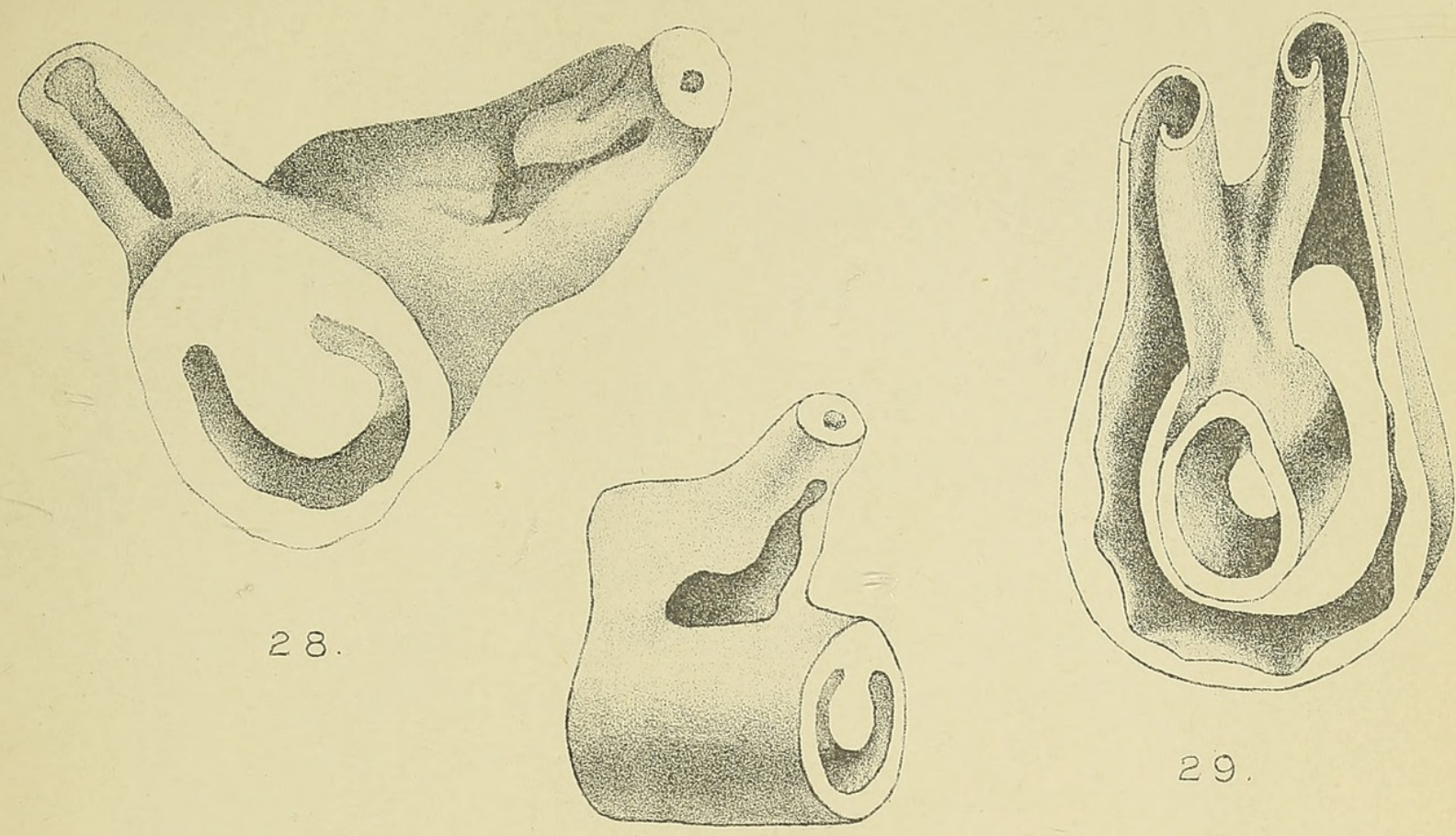

29

\section{7}

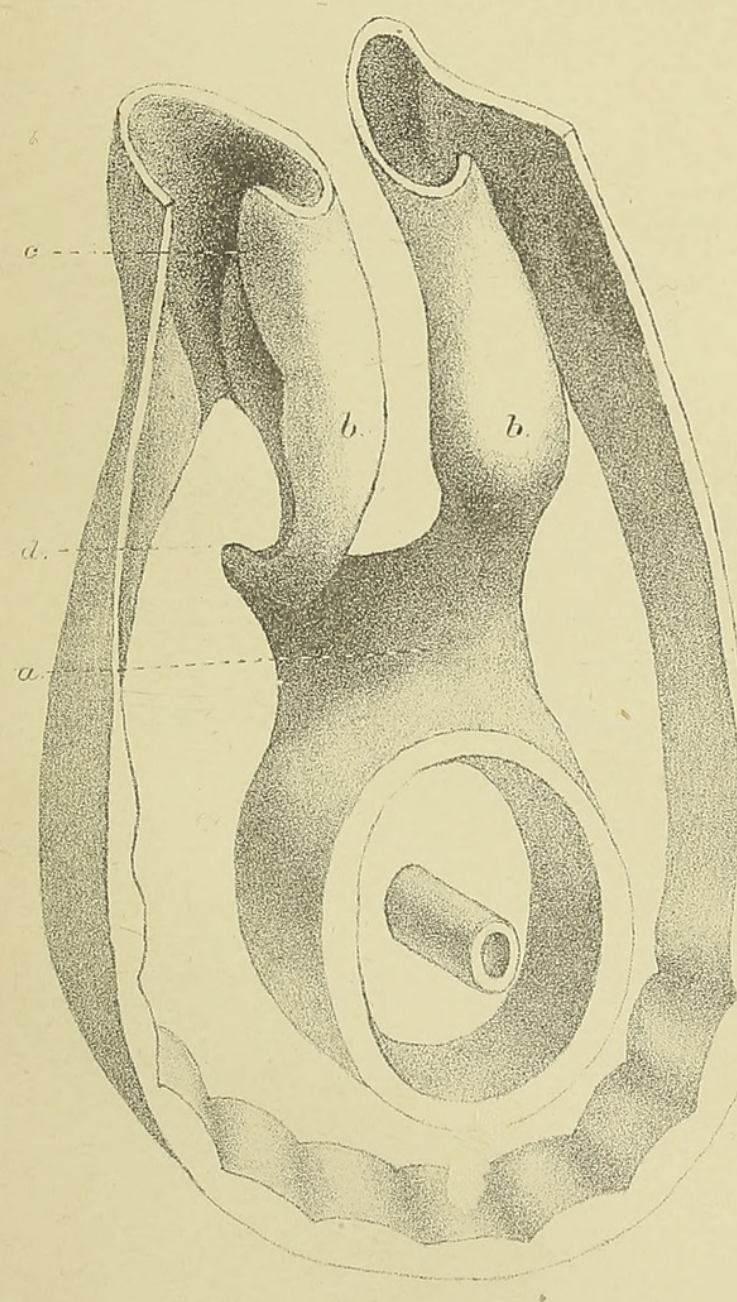

30

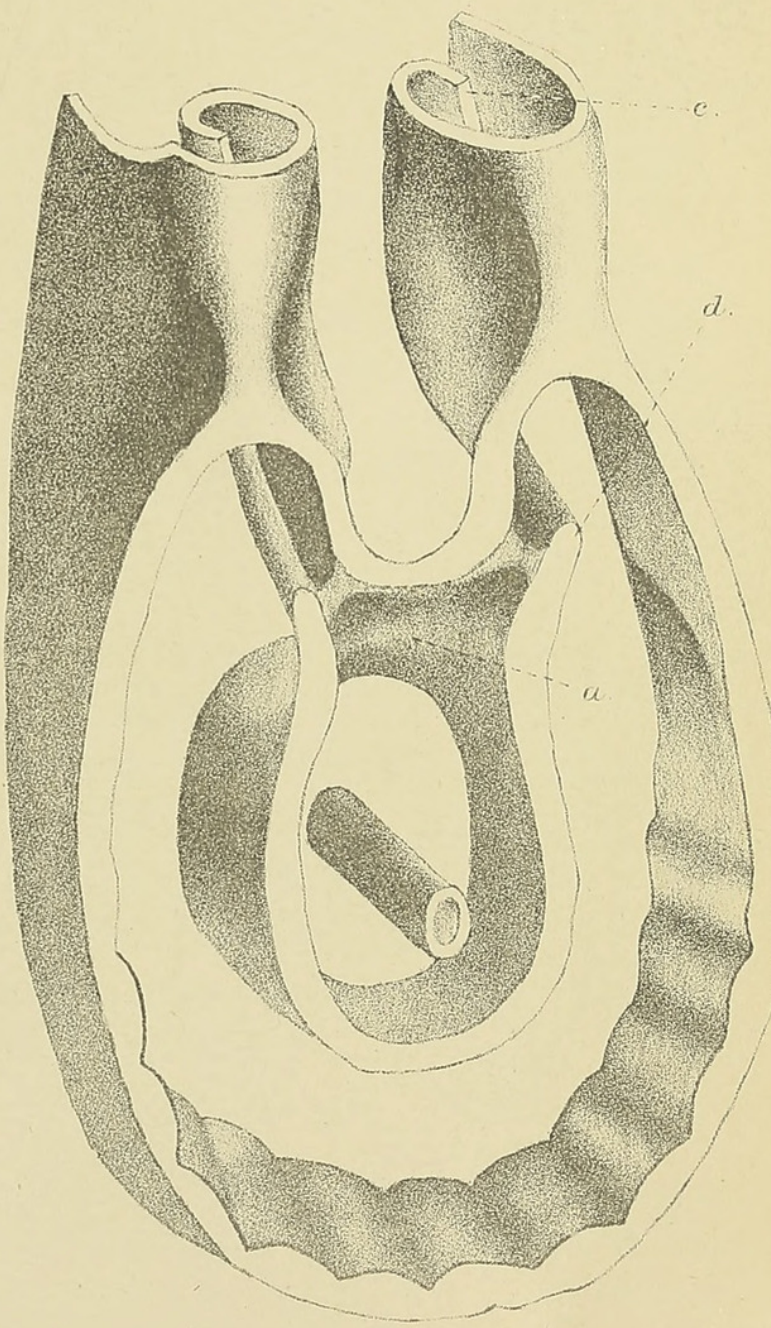

31. 


\section{$2 \mathrm{BHL}$ Biodiversity Heritage Library}

Tansley, A. G. and Lulham, Rosalie Blanche Jermaine. 1905. "A study of the vascular system of Matonia pectinata." Annals of botany 19, 475-519. https://doi.org/10.1093/oxfordjournals.aob.a089015.

View This Item Online: https://www.biodiversitylibrary.org/item/233541

DOI: https://doi.org/10.1093/oxfordjournals.aob.a089015

Permalink: https://www.biodiversitylibrary.org/partpdf/318813

\section{Holding Institution}

Smithsonian Libraries

\section{Sponsored by}

Biodiversity Heritage Library

\section{Copyright \& Reuse}

Copyright Status: Not in copyright. The BHL knows of no copyright restrictions on this item.

This document was created from content at the Biodiversity Heritage Library, the world's largest open access digital library for biodiversity literature and archives. Visit BHL at https://www.biodiversitylibrary.org. 